Article

\title{
Comparative In Vitro Toxicology of Novel Cytoprotective Short-Chain Naphthoquinones
}

\author{
Zikai Feng ${ }^{1,2, *} \mathbb{1}$, Mohammed Sedeeq ${ }^{1}$, Abraham Daniel ${ }^{1}{ }^{1}$, Monika Corban ${ }^{1}$, \\ Krystel L. Woolley ${ }^{2}$, Ryan Condie ${ }^{2}$, Iman Azimi ${ }^{1}{ }^{\circledR}$, Jason A. Smith ${ }^{2}$ and Nuri Gueven ${ }^{1, *} \mathbb{C}$ \\ 1 School of Pharmacy and Pharmacology, University of Tasmania, Hobart, TAS 7005, Australia; \\ mohammed.sedeeq@utas.edu.au (M.S.); abraham.daniel@utas.edu.au (A.D.); \\ monika.corban@utas.edu.au (M.C.); iman.azimi@utas.edu.au (I.A.) \\ 2 School of Natural Sciences, University of Tasmania, Hobart, TAS 7005, Australia; \\ krystel.woolley@utas.edu.au (K.L.W.); ryan.condie@utas.edu.au (R.C.); jason.smith@utas.edu.au (J.A.S.) \\ * Correspondence: zikai.feng@utas.edu.au (Z.F.); nuri.guven@utas.edu.au (N.G.)
}

Received: 30 July 2020; Accepted: 5 August 2020; Published: 7 August 2020

\begin{abstract}
Short-chain quinones (SCQs) have been identified as potential drug candidates against mitochondrial dysfunction, which largely depends on the reversible redox characteristics of the active quinone core. We recently identified 11 naphthoquinone derivatives, 1-11, from a library of SCQs that demonstrated enhanced cytoprotection and improved metabolic stability compared to the clinically used benzoquinone idebenone. Since the toxicity properties of our promising SCQs were unknown, this study developed multiplex methods and generated detailed toxicity profiles from 11 endpoint measurements using the human hepatocarcinoma cell line HepG2. Overall, the toxicity profiles were largely comparable across different assays, with simple standard assays showing increased sensitivity compared to commercial toxicity assays. Within the 11 naphthoquinones tested, the L-phenylalanine derivative 4 consistently demonstrated the lowest toxicity across all assays. The results of this study not only provide useful information about the toxicity features of SCQs but will also enable the progression of the most promising drug candidates towards their clinical use.
\end{abstract}

Keywords: mitochondria; short-chain quinone; idebenone; cytotoxicity

\section{Introduction}

Mitochondrial dysfunction causes a large number of diverse mitochondrial diseases, such as Friedreich's ataxia (FA) [1], Leigh syndrome (LS) [2], mitochondrial encephalopathy, lactic acidosis, stroke-like episodes syndrome (MELAS) [3], maternally inherited diabetes and deafness (MIDD) [4], Leber's hereditary optic neuropathy (LHON) [5], and dominant optic atrophy (DOA) [6]. Mitochondrial dysfunction is also described for many common inflammatory (i.e., ulcerative colitis) [7], neurodegenerative (i.e., Alzheimer's disease, Parkinson's disease, glaucoma, age-related macular degeneration) [8], neuromuscular (i.e., Duchenne muscular dystrophy (DMD), multiple sclerosis) [9], and metabolic disorders (i.e., diabetes, obesity) [10]. However, despite the high incidence of disorders with a mitochondrial pathology, there is a scarcity of approved drugs that aim to directly protect against mitochondrial dysfunction. This significant unmet medical need requires new drug candidates that could be of benefit to a multitude of indications. Potential drug candidates that protect against mitochondrial dysfunction include short-chain quinones (SCQs), which possess reversible redox characteristics due to their quinone core [11-13]. Several SCQs are currently in clinical development. The vitamin E derivative vatiquinone (EPI-743/PTC-743), an antioxidant that targets NAD(P)H:quinone oxidoreductase 1 (NQO1), was initially developed for FA (Phase II, NCT01962363, $3 \times 400 \mathrm{mg}$ for 18 months, with reported improved neurological functions) [14] and LS (Phase II, NCT01721733, 
$3 \times 100 \mathrm{mg}$ for 6 months, with reported improved movement) [15], and was recently acquired by PTC Therapeutics. Another vitamin E derivative, sonlicromanol (KH176, Khondrion), a reactive oxygen species (ROS) modulator, is in development for MELAS and MIDD (Phase II, NCT02909400, $2 \times 100 \mathrm{mg}$ for 28 days, with reported tolerance and safety) [16], LS and LHON (Phase I, NCT02544217, $800 \mathrm{mg}$ for 7 days, with reported tolerance) [17]. The only drug currently available to patients is benzoquinone idebenone, which protects against vision loss and has even restored visual acuity in some LHON patients [18]. Especially for the subgroup of recently affected patients, idebenone has been shown to improve visual acuity and color vision $[19,20]$. A recent report also suggested that idebenone ameliorated mitochondrial complex I deficiency and stabilized/restored visual acuity in patients with DOA [6,21]. In contrast, earlier phase III clinical trials (NCT00905268; NCT00537680) in FA patients were unable to demonstrate therapeutic efficacy for idebenone [22]. Based on its cytoprotective activity under the conditions of mitochondrial dysfunction (hereafter referred to as mito-protection), idebenone was suggested for a wide range of disorders. Contrary to the widespread belief that idebenone is a $\mathrm{CoQ}_{10}$ analogue and acts as antioxidant, recent reports paint a very different picture: idebenone was reported to directly bind and inhibit p52Shc at nanomolar concentration [23], but also acts as PPAR $\alpha / \gamma$ agonist, albeit at higher concentrations [24]. Finally, idebenone activates the expression of Lin28A in vivo, which was shown to be required for retinal neuroprotection and recovery of vision [25]. Although it is unclear at present if these activities of idebenone are causally connected, they all converge to activate Akt signalling, which alters metabolic functions, increases insulin sensitivity, increases mitochondrial function and stress resistance, and induces tissue repair. Although idebenone has consistently demonstrated very good safety in healthy subjects $(2250 \mathrm{mg} /$ day, 14 days) [26] and different patient groups (LHON patients: $900 \mathrm{mg} /$ day, 24 weeks [18]; DMD patients: $900 \mathrm{mg} /$ day, 52 weeks [27]), its efficacy is restricted by its limited absorption, a rapid first-pass effect [28], and its reliance on a single reductase for its bioactivation $[12,13]$.

We recently reported the design and synthesis of a library of $>148$ novel short-chain naphthoquinone derivatives [29] to overcome the known limitations of idebenone, such as limited bioactivation and rapid metabolic inactivation. From this library, 11 compounds (1-11, Table 1) showed significantly improved cytoprotective activity under the conditions of mitochondrial dysfunction and increased metabolic stability in vitro compared to idebenone [29,30]. The current study aimed to compare the in vitro toxicity of these 11 compounds against idebenone to identify possible drug candidates that could be progressed towards clinical development. 
Table 1. Chemical structure, physical properties, in vitro efficacy, and stability of the benzoquinone idebenone and 11 novel naphthoquinone derivatives

\begin{tabular}{|c|c|c|c|c|c|c|c|c|c|c|c|}
\hline \multirow[t]{2}{*}{ Compound } & \multirow{2}{*}{ Structure } & \multirow[t]{2}{*}{$\mathbf{N}$} & \multirow{2}{*}{$\mathbf{R}$} & \multirow{2}{*}{ Formula } & \multirow{2}{*}{$\begin{array}{c}\text { Molecular } \\
\text { Weight } \\
\text { (g/mol) }\end{array}$} & \multirow[t]{2}{*}{$\log P^{1}$} & \multirow[t]{2}{*}{$\log D^{2}$} & \multicolumn{2}{|c|}{ In Vitro Cytoprotection ${ }^{3}$} & \multicolumn{2}{|c|}{$\begin{array}{l}\text { In Vitro Metabolic } \\
\text { Stability }^{4}\end{array}$} \\
\hline & & & & & & & & $\%$ & $p$-Value & $\%$ & $p$-Value \\
\hline Idebenone & & - & - & $\mathrm{C}_{19} \mathrm{H}_{30} \mathrm{O}_{5}$ & 338.4 & 1.24 & 3.57 & $66.2 \pm 12.0$ & - & $27.3 \pm 3.9$ & - \\
\hline $\begin{array}{c}1 \\
\text { (UTAS\#81) }\end{array}$ & & & & $\mathrm{C}_{23} \mathrm{H}_{23} \mathrm{NO}_{4}$ & 377.4 & 2.24 & 2.81 & $83.8 \pm 19.9$ & 0.191 & $92.6 \pm 16.9$ & $<0.001$ \\
\hline $\begin{array}{c}2 \\
\text { (UTAS\#80) }\end{array}$ & & 2 & & $\mathrm{C}_{23} \mathrm{H}_{23} \mathrm{NO}_{4}$ & 377.4 & 2.24 & 2.81 & $87.6 \pm 19.7$ & 0.025 & $96.6 \pm 11.1$ & $<0.001$ \\
\hline $\begin{array}{c}3 \\
\text { (UTAS\#62) }\end{array}$ & & & & $\mathrm{C}_{24} \mathrm{H}_{25} \mathrm{NO}_{4}$ & 391.5 & 2.52 & 3.10 & $93.1 \pm 13.7$ & $<0.001$ & $84.0 \pm 15.5$ & $<0.001$ \\
\hline $\begin{array}{c}4 \\
\text { (UTAS\#37) }\end{array}$ & & 2 & & $\mathrm{C}_{24} \mathrm{H}_{23} \mathrm{NO}_{5}$ & 405.4 & 2.48 & 0.12 & $100.3 \pm 17.3$ & $<0.001$ & $96.0 \pm 7.5$ & $<0.001$ \\
\hline $\begin{array}{c}5 \\
\text { (UTAS\#72) }\end{array}$ & & 3 & & $\mathrm{C}_{25} \mathrm{H}_{25} \mathrm{NO}_{5}$ & 419.5 & 2.90 & 0.74 & $90.7 \pm 15.6$ & 0.146 & $91.4 \pm 0.8$ & $<0.001$ \\
\hline $\begin{array}{c}6 \\
\text { (UTAS\#74) }\end{array}$ & & 2 & & $\mathrm{C}_{23} \mathrm{H}_{23} \mathrm{NO}_{4}$ & 377.4 & 2.67 & 3.43 & $91.7 \pm 15.6$ & 0.101 & $45.7 \pm 2.9$ & 0.034 \\
\hline $\begin{array}{c}7 \\
\text { (UTAS\#88) }\end{array}$ & & 3 & & $\mathrm{C}_{24} \mathrm{H}_{25} \mathrm{NO}_{4}$ & 391.5 & 3.09 & 3.87 & $91.8 \pm 9.8$ & 0.097 & $60.3 \pm 1.7$ & $<0.001$ \\
\hline $\begin{array}{c}8 \\
\text { (UTAS\#54) }\end{array}$ & & & & $\mathrm{C}_{21} \mathrm{H}_{25} \mathrm{NO}_{5}$ & 371.4 & 2.04 & 0.26 & $98.7 \pm 10.9$ & 0.004 & $84.3 \pm 9.2$ & $<0.001$ \\
\hline $\begin{array}{c}9 \\
\text { (UTAS\#77) }\end{array}$ & & & & $\mathrm{C}_{25} \mathrm{H}_{27} \mathrm{NO}_{5}$ & 421.5 & 2.80 & 3.41 & $95.9 \pm 19.4$ & 0.017 & $58.3 \pm 11.0$ & $<0.001$ \\
\hline $\begin{array}{c}10 \\
\text { (UTAS\#61) }\end{array}$ & & - & & $\mathrm{C}_{20} \mathrm{H}_{23} \mathrm{NO}_{4}$ & 341.4 & 1.06 & 1.71 & $100.7 \pm 28.4$ & 0.002 & $78.9 \pm 7.4$ & $<0.001$ \\
\hline $\begin{array}{c}11 \\
\text { (UTAS\#43) }\end{array}$ & & - & & $\mathrm{C}_{20} \mathrm{H}_{21} \mathrm{NO}_{5}$ & 355.4 & 1.02 & -1.32 & $92.7 \pm 7.6$ & 0.018 & $67.2 \pm 2.3$ & $<0.001$ \\
\hline
\end{tabular}

${ }^{1}$ LogP was predicted using ChemDraw Professional software (version 16.0, PerkinElmer, MA, USA). ${ }^{2}$ LogD was predicted using MarvinView software (version 19.25, ChemAxon, Budapest, Hungary). ${ }^{3}$ In vitro cytoprotection of HepG2 by $10 \mu \mathrm{M}$ SCQs against rotenone-induced mitochondrial complex I dysfunction. Cytoprotection was calculated as a relative percentage of cell survival compared to untreated cells $(26.9 \pm 7.9 \%)$. Data was expressed as mean \pm standard deviation (SD) [29]. ${ }^{4}$ In vitro metabolic stability of $40 \mu \mathrm{M} \mathrm{SCQs} \mathrm{over} 6 \mathrm{~h}$ on HepG2. Stability was calculated as percentage compounds found remaining after $6 \mathrm{~h}$. Data was expressed as mean \pm SD [30] 


\section{Results}

\subsection{WST-1 Assay}

This study aimed to assess the in vitro toxicity of our test compounds in the hepatic cell line HepG2 across a range of assays to measure different toxicity-related endpoints including metabolic toxicity, membrane integrity, mitochondrial toxicity, mechanisms of cell death, DNA damage, and transformation potential. When cellular $\mathrm{NAD}(\mathrm{P}) \mathrm{H}$ synthesis as a surrogate marker for cellular metabolism was measured using the widely employed WST-1 dye, the reference compound idebenone significantly reduced WST-1 absorption from $150 \mu \mathrm{M}$ onwards ( $p<0.001$; Figure 1a). In comparison, most test compounds already reduced absorption from $25 \mu \mathrm{M}$ (3 and 8), $50 \mu \mathrm{M}(\mathbf{1}, \mathbf{2}$, and 9-11), and $75 \mu \mathrm{M}$ (6 and 7) onwards, respectively ( $p<0.033$; see Table S1 for full dataset). In contrast, compared to the untreated control cells, a significant reduction of WST-1 absorption by compounds 4 and 5 was only observed from $175 \mu \mathrm{M}$ onwards $(p<0.002)$ and $200 \mu \mathrm{M}(p<0.001)$, respectively. Compared to idebenone, compounds 4 and 5 from $150 \mu \mathrm{M}$ onwards reduced WST-1 absorption significantly less $(p<0.001)$.

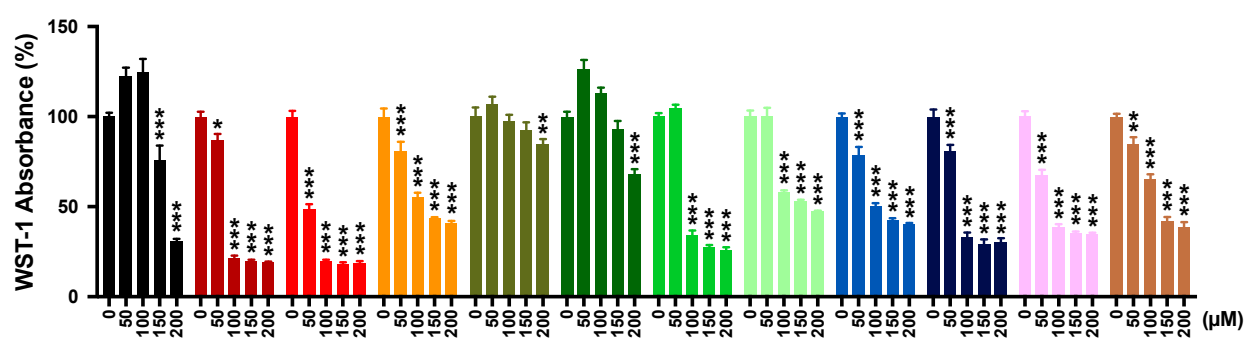

(a)

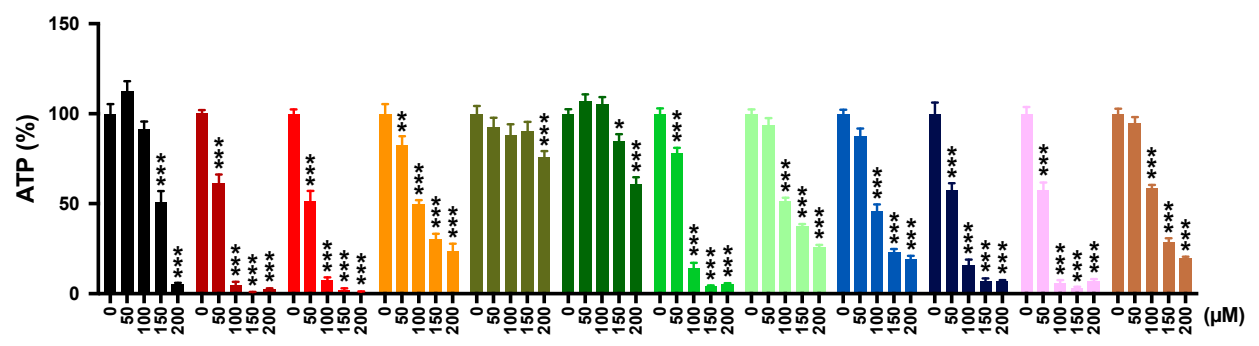

(b)

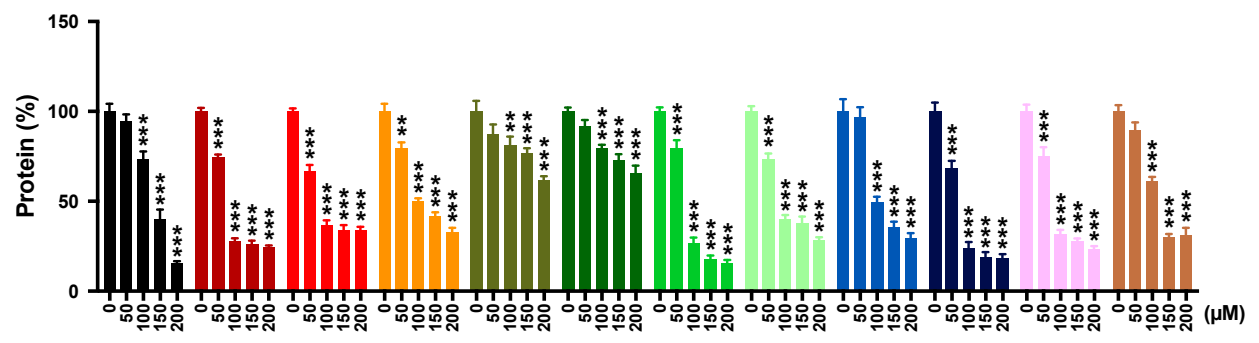

(c)

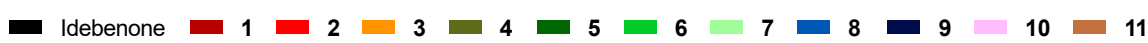

Figure 1. Effect of test compounds on metabolic toxicity. Cells were exposed to reference and test compounds $(0-200 \mu \mathrm{M})$ for $24 \mathrm{~h}$ before (a) WST-1 absorption; (b) ATP levels; (c) protein contents were quantified. Data represents mean \pm SEM of 3 independent experiments with 6 parallel wells per experiment. Two-way ANOVA was performed to compare test concentrations against the non-treated control: ${ }^{* * *} p<0.001,{ }^{* *} p<0.002,{ }^{*} p<0.033$. Full datasets shown in Tables S1-S3. 


\subsection{ATP Levels}

As another marker of metabolic toxicity, cellular ATP levels were assessed in the absence or presence of the reference or test compounds. The reference compound idebenone significantly reduced ATP levels from $125 \mu \mathrm{M}$ onwards $(p<0.001$; Figure $1 \mathrm{~b}$, Table S2). Similar to the WST-1 results, a significant reduction was only observed at $200 \mu \mathrm{M}$ by compound 4 and from $150 \mu \mathrm{M}$ onwards by compound $\mathbf{5}(p<0.033)$, respectively, while other compounds already significantly reduced ATP levels from 50-75 $\mu \mathrm{M}$ compared to the untreated cells $(p<0.033$; Table S1). Compared to idebenone, compounds 4 and 5 showed a significantly lower effect on ATP levels $(p<0.001)$ from 150 and $125 \mu \mathrm{M}$ onwards, respectively (Figure 1b; Table S2).

\subsection{Protein Levels}

Since our test compounds had similar effects on both ATP levels and the conversion of WST-1 dye, we assessed the levels of protein per well as a surrogate marker for cellular content. The reference compound idebenone significantly reduced protein levels from $100 \mu \mathrm{M}$ onwards $(p<0.001$; Figure $1 c)$. Of 11 tested compounds, 4 and 5 significantly reduced protein levels from $100 \mu \mathrm{M}$ onwards $(p<0.002)$, while significant reductions by the other compounds were already evident at 50-75 $\mu \mathrm{M}(p<0.001$; Table S3). At higher concentrations from $125 \mu \mathrm{M}$ onwards, compounds 4 and 5 affected protein levels significantly less than idebenone $(p<0.001)$.

\subsection{Membrane Integrity}

Propidium iodide (PI) staining was employed as a measurement of impaired membrane integrity. The reference compound idebenone significantly increased PI incorporation from $100 \mu \mathrm{M}$ onwards $(p<0.033$; Figure 2a). Of 11 tested compounds, 4 did not increase PI incorporation significantly at all tested concentrations, while 2 compounds increased from $150 \mu \mathrm{M}(5, p<0.033 ; \mathbf{1 1}, p<0.001)$, 1 compound from $125 \mu \mathrm{M}(8, p<0.001), 1$ compound from $100 \mu \mathrm{M}(7, p<0.001), 4$ compounds from $75 \mu \mathrm{M}(\mathbf{3}, \mathbf{6}, 9$ and 10, $p<0.001)$, and 2 compounds from $50 \mu \mathrm{M}$ onwards $(\mathbf{1}, p<0.033 ; 2, p<0.001$; Table S1). Compared to idebenone, the observed effects by compounds $\mathbf{4}, \mathbf{5}$, and $\mathbf{1 1}$ was significantly lower from $100 \mu \mathrm{M}$ onwards, at $125-150 \mu \mathrm{M}$, and at 100-125 $\mu \mathrm{M}$, respectively $(p<0.033$; Table S4), while the effect by compound 8 was not statistically significant, and the effects by the other derivatives were significantly higher between 50 and $200 \mu \mathrm{M}$.

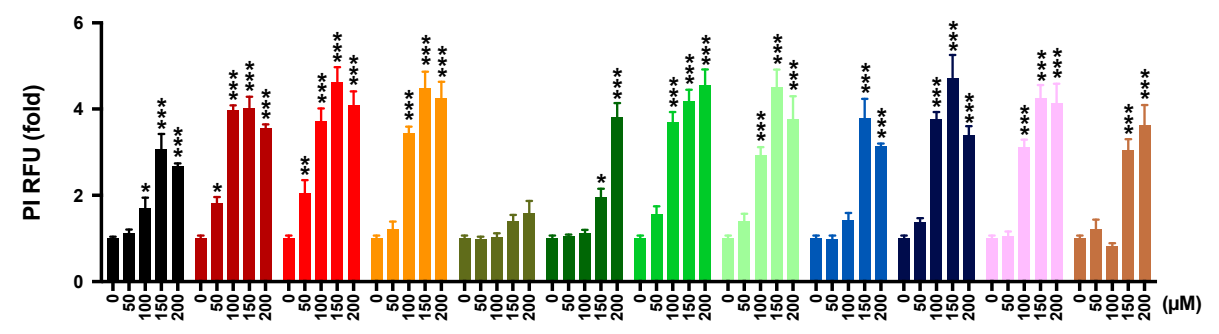

(a)

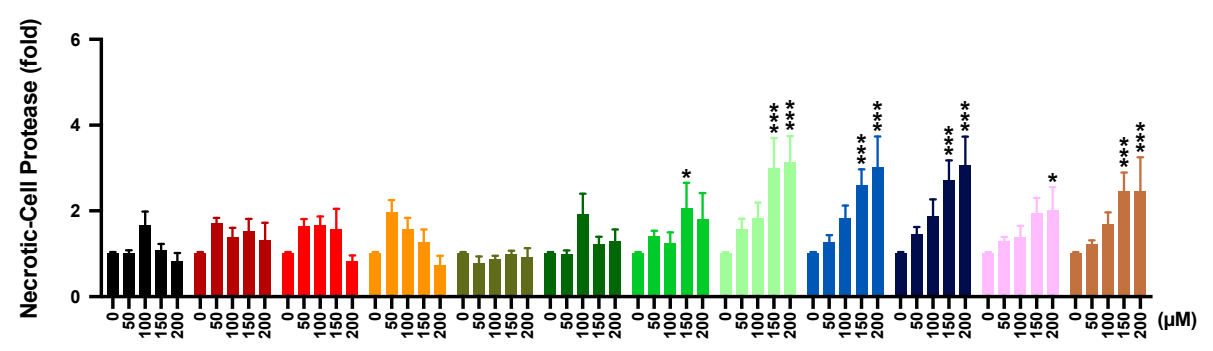

(b)

Figure 2. Cont. 


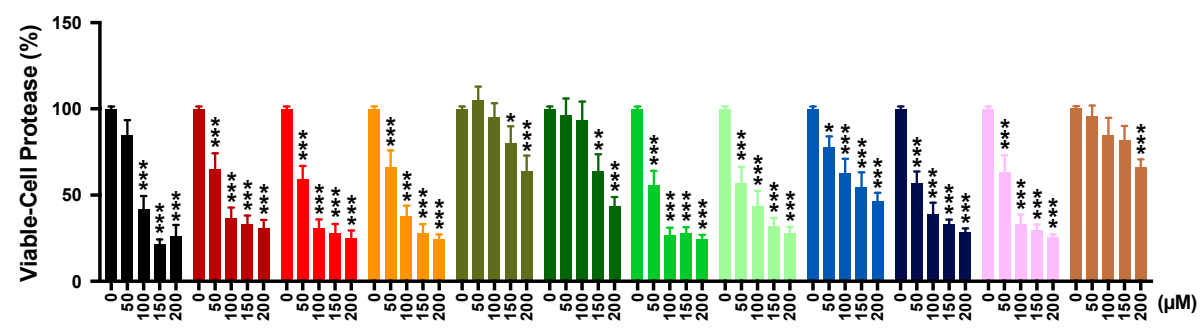

(c)

Figure 2. Effect of test compounds on membrane integrity. Cells were exposed to reference or test compounds (0-200 $\mu \mathrm{M})$ for $24 \mathrm{~h}$ before (a) propidium iodide (PI) incorporation; (b) necrotic-cell protease activity, and (c) viable-cell protease activity (Multi-Tox Fluor Kit) were assessed. Data represents mean \pm SEM from 3 independent experiments with 4 parallel wells per experiment. Two-way ANOVA was performed to compare test concentrations against the non-treated control: ${ }^{* *} p<0.001,{ }^{* *} p<0.002$, ${ }^{*} p<0.033$. Full datasets shown in Tables S4-S6. RFU, relative fluorescence units.

\subsection{Multi-Tox Fluor Assay}

Based on the effects of the test compounds on PI staining, we assessed cell membrane integrity using a commercially available kit that proposed to simultaneously assess this endpoint and cell viability. The reference compound idebenone did not significantly increase bis-AAF-R110 fluorescence, which is indicative of a lack of necrotic-cell protease activity at all test concentrations (Figure 2b). Of the 11 tested compounds, 5 compounds did not significantly increase bis-AAF-R110 fluorescence at any concentration (1-5), while compound 10 increased fluorescence at $200 \mu \mathrm{M}(p<0.033)$, compound 6 increased at 125-150 $\mu \mathrm{M}(p<0.033)$, and four other compounds increased fluorescence from $125 \mu \mathrm{M}$ onwards (7-9 and 11, $p<0.001$; Table S5). Compared to the effects of idebenone, no significant increases by compounds 1-6 were observed, while compound 10 showed significantly higher levels of bis-AAF-R110 fluorescence at $200 \mu \mathrm{M}$ ( $p<0.033), 3$ compounds from $150 \mu \mathrm{M}$ onwards (8 and $\mathbf{9}$, $p<0.002 ; 11, p<0.033)$, and compound 7 from $125 \mu \mathrm{M}$ onwards $(p<0.033$; Table S5), respectively.

While bis-AAF-R110 measures the activity of the necrosis-associated protease, the protease substrate GF-AFC is thought to measure live cells with intact plasma membrane. In our test system, idebenone significantly reduced GF-AFC fluorescence from $75 \mu \mathrm{M}$ onwards $(p<0.001$; Figure 2c, Table S6). In contrast, a significant reduction by compounds 4, 5, and $\mathbf{1 1}$ were only observed from 150, 125 , and $175 \mu \mathrm{M}$ onwards $(p<0.033)$, respectively. However, the remaining 8 compounds significantly reduced fluorescence already at $25-50 \mu \mathrm{M}(p<0.033$; Table S6). Compared to idebenone, a significantly lower reduction of fluorescence was detected for compounds 4, 5, and 11 from $75 \mu \mathrm{M}$ onwards $(p<0.001$, Table S6).

\subsection{Mitochondrial Superoxide Production}

To further assess if the observed toxicity of the test compounds could be attributed to mitochondrial toxicity, mitochondrial superoxide production was measured. Antimycin A, used as a positive control in our test system [31], significantly increased the fluorescence of the mitochondrial superoxide indicator MitoSOX from $25 \mu \mathrm{M}$ onwards $(p<0.001$, Table S7), while idebenone did not increase MitoSOX fluorescence across all tested concentrations (Figure 3). Of the 11 test compounds, 3 compounds significantly increased MitoSOX fluorescence to different degrees $(5,200 \mu \mathrm{M}, p<0.033 ; 8, \geq 100 \mu \mathrm{M}$, $p<0.033 ; 11, \geq 100 \mu \mathrm{M}, p<0.002)$, while for the 8 other test compounds no significant increases were detected. The observed increases by the 3 test compounds $(5,8$, and 11) were significantly lower compared to antimycin A for all concentrations $(p<0.001)$. Compared to idebenone, compounds $\mathbf{5 , 8}$, and 11 significantly increased MitoSOX fluorescence from $150 \mu \mathrm{M}(p<0.033), 75 \mu \mathrm{M}(p<0.033)$ and $75 \mu \mathrm{M}(p<0.002)$ onwards, respectively (Figure 3$)$. 


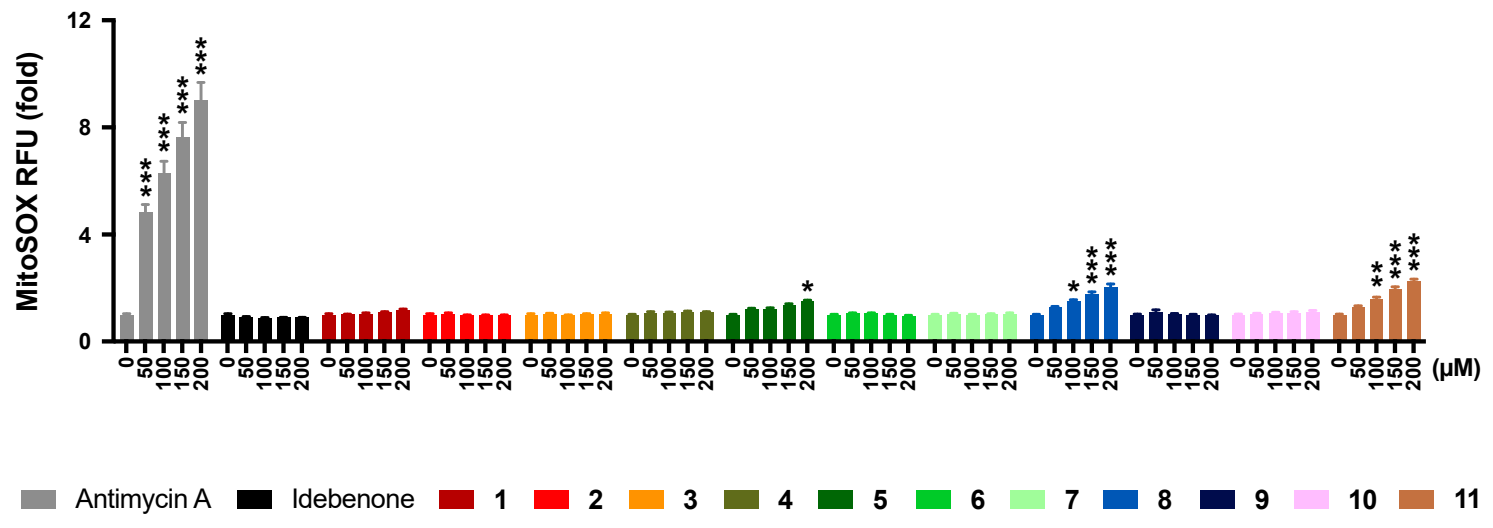

Figure 3. Effect of test compounds on mitochondrial superoxide production. Cells were exposed to reference (antimycin A, idebenone) or test compounds (0-200 $\mu \mathrm{M})$ for $30 \mathrm{~min}$ before mitochondrial superoxide levels were quantified. Data was expressed as mean \pm SEM of 3 independent experiments with 8 parallel wells per experiment. Two-way ANOVA was performed to compare test concentrations against the non-treated control: ${ }^{* *} p<0.001,{ }^{* *} p<0.002,{ }^{*} p<0.033$. Full datasets available in Table S7.

\subsection{Colony Formation}

Long-term toxicity was assessed using a standard colony formation assay, where the reference compound idebenone significantly reduced colony formation from $10 \mu \mathrm{M}$ onwards ( $p<0.002$; Figure 4 ). Of the 11 test compounds, compounds 4 and $\mathbf{5}$ significantly reduced colony numbers from $20 \mu \mathrm{M}$ $(p<0.001)$ and $10 \mu \mathrm{M}(p<0.002)$ onwards, respectively, while all other compounds already showed a significant reduction in colony numbers at $5 \mu \mathrm{M}(p<0.001$; Table S8). The effects of compounds 4 and 5 were significantly lower across all test concentrations $(p<0.001)$, compared to the other test compounds.

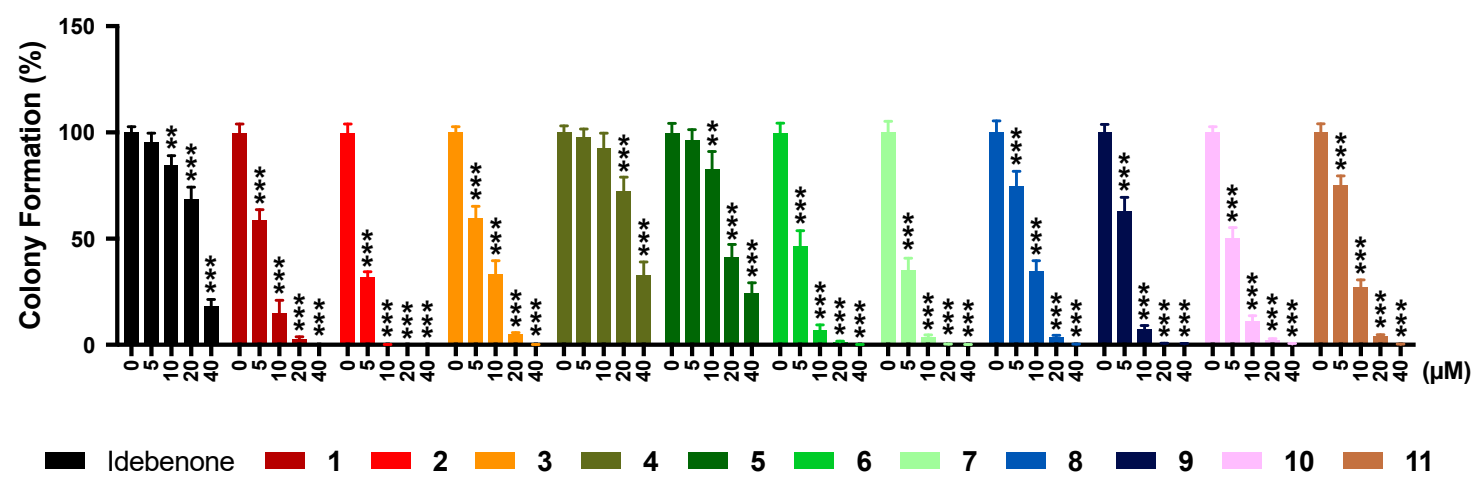

Figure 4. Effect of test compounds on colony formation. Cells were exposed to reference or test compounds $(0-100 \mu \mathrm{M})$ for 14 days before colonies ( $>50$ cells) were quantified. Data was expressed as mean \pm SEM of 3 independent experiments with 4 parallel wells per experiment. Two-way ANOVA was performed to compare test concentrations against the non-treated control: ${ }^{* * *} p<0.001,{ }^{* *} p<0.002$. Full datasets available in Table S8.

\subsection{Nuclear Morphology}

The previous results suggested that the observed toxicity at higher concentrations was mainly associated with a loss of cells and/or impaired cell membrane integrity, which is indicative of reduced proliferation and/or cell death. High content imaging was used to simultaneously quantify nuclei numbers per field of vision, nuclear size, and fluorescence intensity as markers of pyknosis, respectively. Using this analysis, the reference compound idebenone, like most test compounds (1-3 and 8-10), significantly reduced nuclei numbers $(p<0.001)$ and nuclear size $(p<0.033)$ and increased nuclear fluorescence $(p<0.002)$ at $100 \mu \mathrm{M}$ (Figure 5). Although 4 compounds (5-7 and 11) significantly reduced 
nuclei numbers $(5, p<0.033 ; 6,7$, and $11, p<0.001)$, no significant changes to the nuclear size or fluorescence intensity were detected. Compound 4 did not significantly change nuclei number, size, or fluorescence intensity. Overall, the individual results of this approach appear mostly consistent in that those compounds which reduce nuclei numbers, also decrease nuclear area and increase nuclear fluorescence (Figure $5 \mathrm{a}-\mathrm{c}$ ).

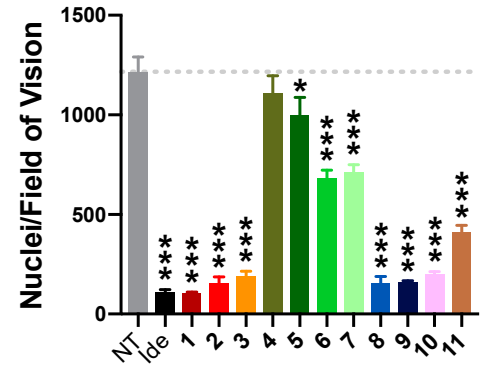

(a)

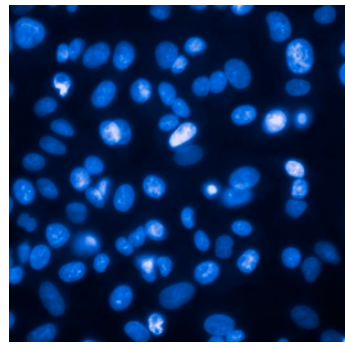

(d)

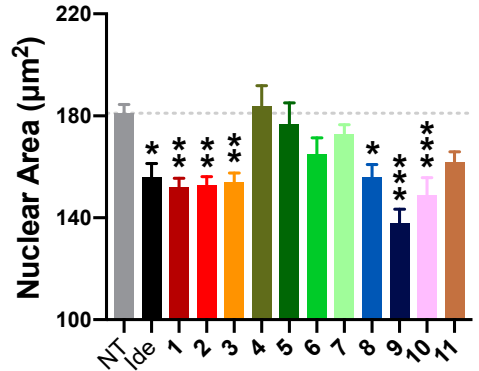

(b)

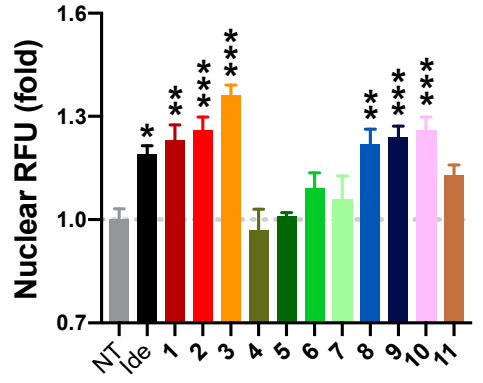

(c)

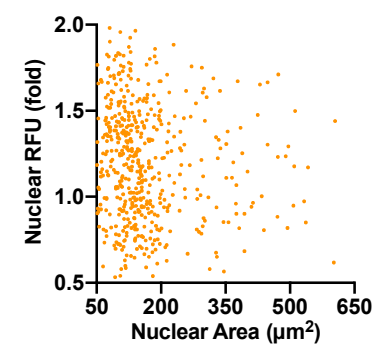

(g)

Figure 5. Effect of test compounds on nuclear count and morphology. Cells were exposed to reference or test compounds $(100 \mu \mathrm{M})$ for $24 \mathrm{~h}$ before (a) nuclear count, (b) area, and (c) intensity were assessed. Exemplary fluorescence images $(60 \times$ magnification $)$ of $(\mathbf{d})$ non-treated $(\mathrm{NT})$ and $(\mathbf{e})$ treated DAPI-stained nuclei; single cell plots of nuclei either (f) NT or (g) treated with compound 3 are presented. Compound $3(\mathbf{e}, \mathbf{g})$ significantly reduced average nuclear count and size, and increased average fluorescence intensity than NT $(\mathbf{d}, \mathbf{f})$. Nuclear RFU was standardized on the average intensity of NT control nuclei and expressed as fold-change. Data represents mean \pm SEM of 8 independent images per treatment. Two-way ANOVA was performed to compare idebenone or test compounds against the non-treated control: ${ }^{* * *} p<0.001,{ }^{* *} p<0.002,{ }^{*} p<0.033$.

\subsection{DNA Damage}

Due to the reported redox nature of the test compounds [29] and the observed reactive oxygen species (ROS) production by some compounds, the possibility of oxidative stress-induced DNA damage was assessed (Figure 6). For this purpose, the structurally related naphthoquinone menadione was used as a positive control [32]. In our test system, menadione significantly increased the number of $\gamma-\mathrm{H}_{2} \mathrm{AX}$-positive cells from $20 \mu \mathrm{M}$ onwards $(p<0.001)$, while no signs of DNA damage by idebenone were detected across all the concentrations tested (Figure 6). Of the 11 test compounds, 3 and 4 did not significantly increase the number of $\gamma-\mathrm{H}_{2} \mathrm{AX}$-positive cells at any concentration, while 2 compounds increased the number of $\gamma-\mathrm{H}_{2} \mathrm{AX}$-positive cells at $40 \mu \mathrm{M}(\mathbf{1 0}, p<0.033 ; \mathbf{1 1}, p<0.001), 5$ compounds increased $\gamma-\mathrm{H}_{2} \mathrm{AX}$-positive cells from $30 \mu \mathrm{M}$ onwards (1, 4, and 9, $p<0.002 ; \mathbf{5}$ and $\mathbf{6}, p<0.033$ ), 1 compound showed an increase from $20 \mu \mathrm{M}(1, p<0.001)$, and 1 compound showed an increase from $10 \mu \mathrm{M}$ onwards $(\mathbf{8}, p<0.033)$. Increased numbers of $\gamma-\mathrm{H}_{2} \mathrm{AX}$-positive cells by 6 compounds ( $3-5$ and 9-11) were significantly lower compared to menadione across all test concentrations $(p<0.033)$ and no significant differences were observed between compounds 3, 4, and idebenone (Figure 6). 


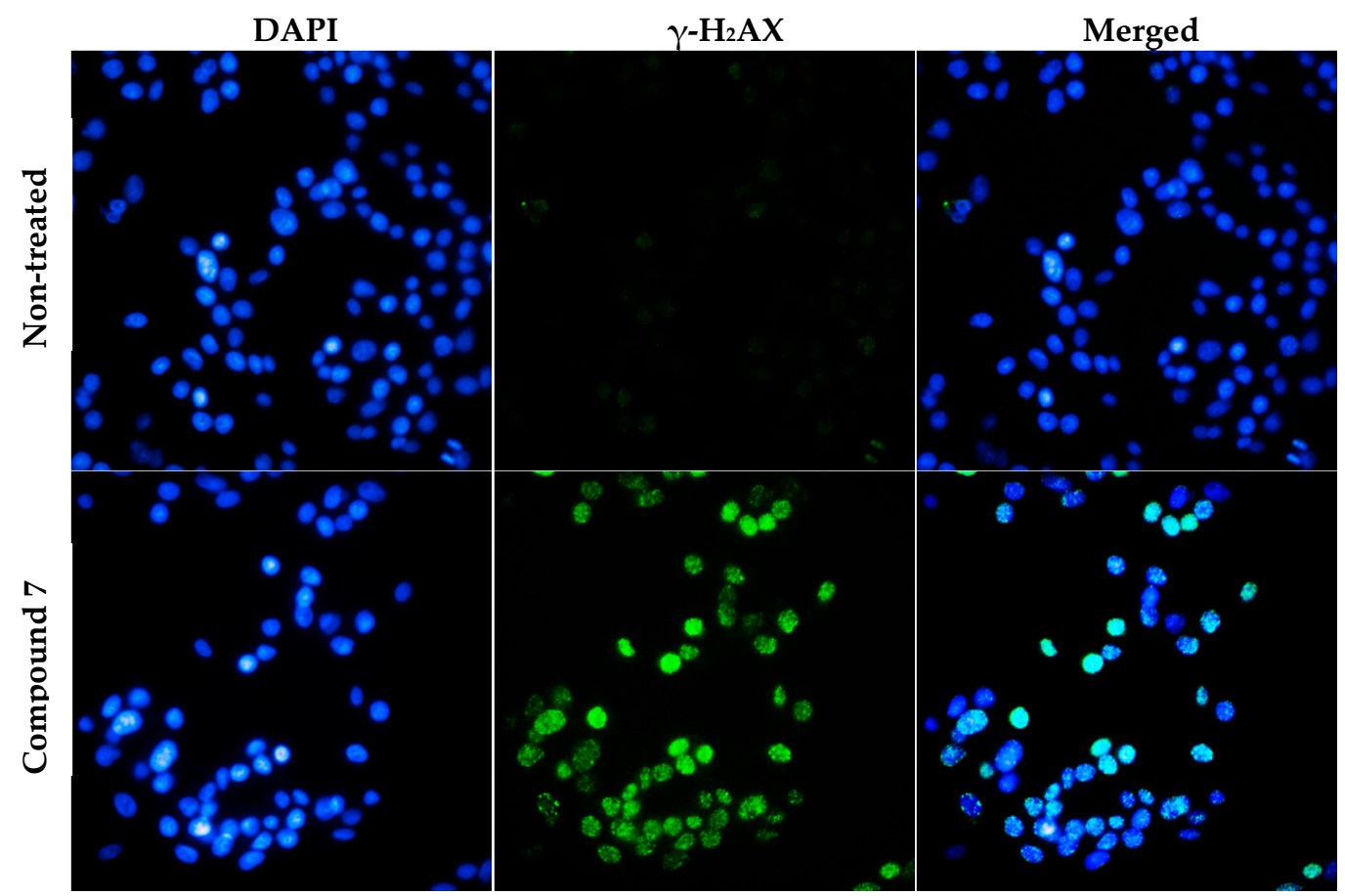

(a)

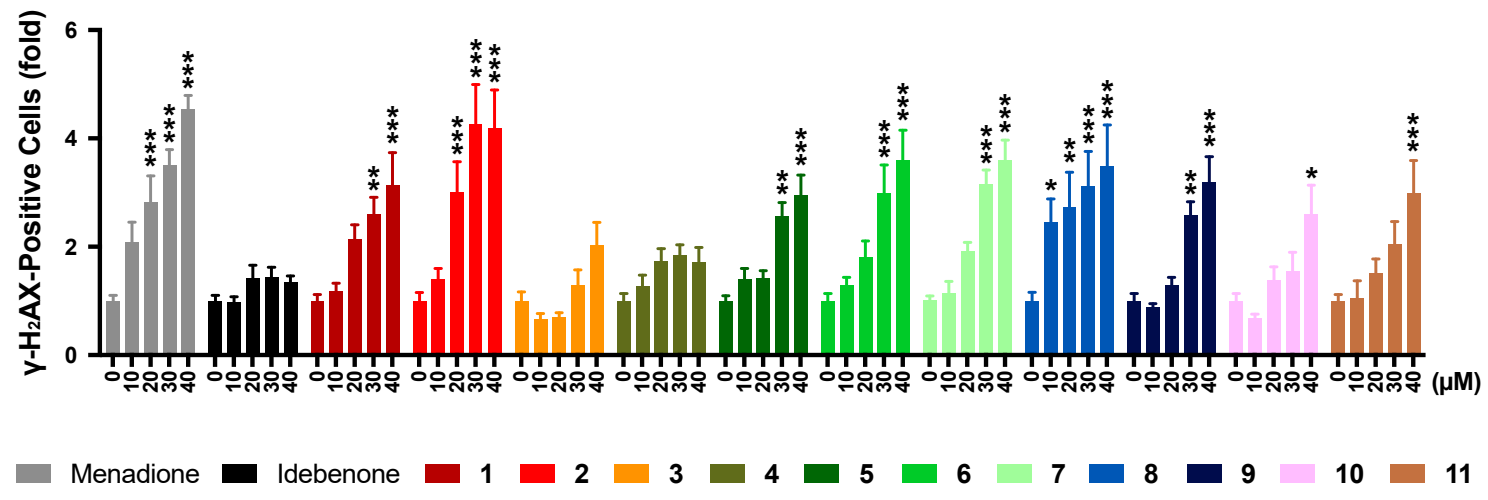

(b)

Figure 6. Effect of test compounds on DNA damage. Cells were exposed to reference compounds (menadione, idebenone) or test compounds $(0-40 \mu \mathrm{M})$ for $4 \mathrm{~h}$ before the presence of nuclear $\gamma-\mathrm{H}_{2} \mathrm{AX}$ positive cells was quantified. (a) Exemplary images $(60 \times$ magnification) used for quantitation of $\gamma-\mathrm{H}_{2} \mathrm{AX}$-positive cells using compound 7 as positive treatment and (b) quantitation of results for all reference and test compounds. Data represent the mean \pm SEM of 3 independent experiments with 4 parallel wells per experiment. Overall, $>1000$ cells were analysed per treatment. Two-way ANOVA was performed to compare test concentrations against the non-treated control: ${ }^{* *} p<0.001,{ }^{* *} p<0.002$, * $p<0.033$.

\subsection{Transformation Potential}

Based on the induction of $\gamma-\mathrm{H}_{2} \mathrm{AX}$, indicative of DNA damage by some test compounds, their potential to transform substrate-dependent growth of HepG2 cells into substrate-independent cell growth by DNA mutations was assessed. To quantify transformation potential of our test compounds, a high throughput variant of the traditional semi-solid agar invasion assay was employed [33] using resorufin fluorescence as the indicator of cell growth [34]. The mutagenic compound 2-amino-1-methyl-6-phenylimidazo[4,5-b]pyridine (PhIP) was used as a positive control [35]. In our test system, PhIP exhibited its reported transformation potential by significantly increasing 
substrate-independent cell growth $(p<0.001$, Figure 7$)$, while neither idebenone nor any of the test compounds significantly increased cell growth at any test concentration. Similar to $\operatorname{PhIP}(p<0.001)$, all reference and test compounds, except for compound 4 , significantly reduced resorufin fluorescence at $40 \mu \mathrm{M}(p<0.002)$ as a consequence of increased compound toxicity. Compared to idebenone, the reduction of resorufin fluorescence by compound 4 was significantly lower across all test concentrations $(p<0.002)$. At $40 \mu \mathrm{M}$, compounds 5 and 11 showed significantly lower inhibitory effects compared to idebenone, whereas all other compounds showed greater inhibition from 10-20 $\mu \mathrm{M}$ onwards $(p<0.002)$.

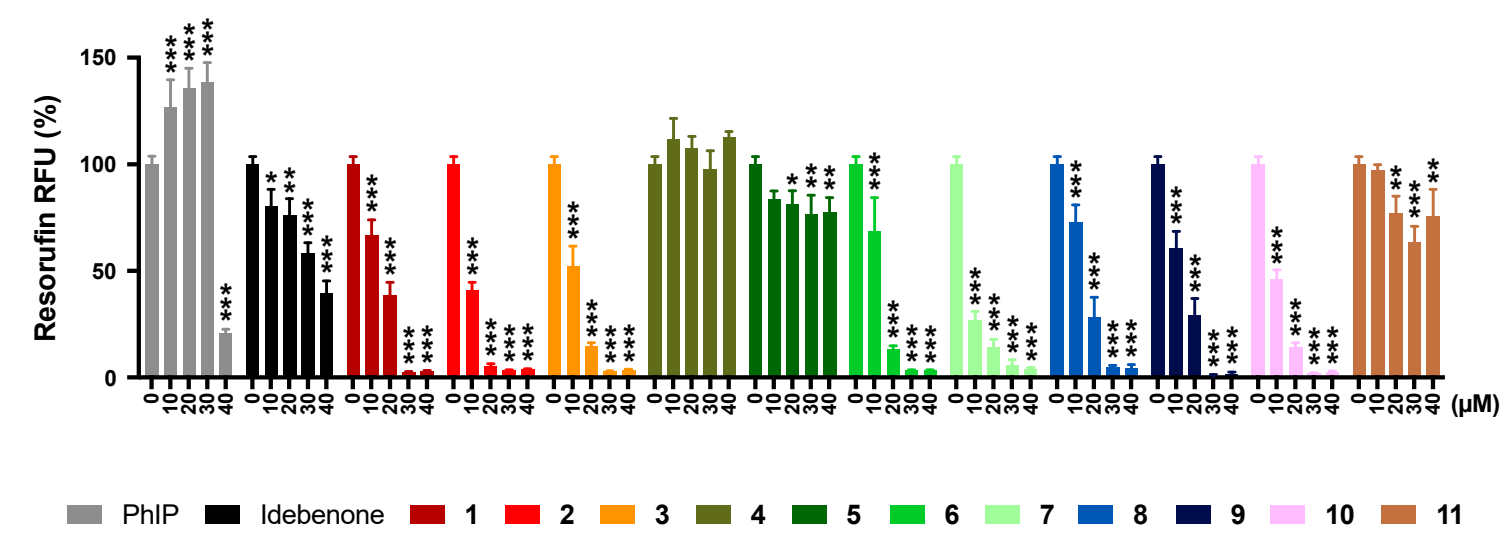

Figure 7. Transformation potential of test compounds. Cells were exposed to reference compounds (PhIP, idebenone) or test compounds $(0-40 \mu \mathrm{M})$ for 21 days in soft agar before cell growth under these conditions was quantified. Data represents the mean \pm SEM of 8 independent wells per treatment. Two-way ANOVA was performed to compare test concentrations against the non-treated control: ${ }^{* * *} p<0.001,{ }^{* *} p<0.002, * p<0.033$.

\subsection{Summary of Results}

Comparative in vitro toxicities of the test compounds 1-11 against the reference compound idebenone are summarized in Table 2. 
Table 2. Summary of the in vitro toxicity of compounds.

\begin{tabular}{|c|c|c|c|c|c|c|c|c|c|c|c|}
\hline \multirow[b]{2}{*}{ Compound } & \multicolumn{3}{|c|}{ Multiplex Detection } & \multirow{2}{*}{$\begin{array}{l}\text { Membrane } \\
\text { Integrity }^{2}\end{array}$} & \multicolumn{2}{|c|}{ Multi-Tox Fluor Assay } & \multirow{2}{*}{$\begin{array}{c}\text { Mitochondrial } \\
\text { Superoxide }^{2}\end{array}$} & \multirow{2}{*}{$\begin{array}{c}\text { Colony } \\
\text { Formation } 1\end{array}$} & \multirow[b]{2}{*}{ Pyknosis } & \multirow{2}{*}{$\begin{array}{c}\text { DNA } \\
\text { Damage }^{2}\end{array}$} & \multirow[b]{2}{*}{$\begin{array}{l}\text { Transformation } \\
\text { Potential }\end{array}$} \\
\hline & WST- $^{1}$ & $\operatorname{ATP}^{1}$ & Protein $^{1}$ & & $\begin{array}{l}\text { Necrotic-Cell } \\
\text { Protease }^{2}\end{array}$ & $\begin{array}{l}\text { Viable-Cell } \\
\text { Protease }^{1}\end{array}$ & & & & & \\
\hline Idebenone & $151.7 \pm 5.9$ & $146.8 \pm 14.2$ & $136.8 \pm 4.7$ & $\geq 100$ & $\mathrm{~N}$ & $71.1 \pm 11.1$ & $\mathrm{~N}$ & $26.0 \pm 5.2$ & $\mathrm{Y}$ & $\mathrm{N}$ & $\mathrm{N}$ \\
\hline 1 & $59.0 \pm 2.2$ & $59.0 \pm 4.7$ & $59.6 \pm 0.6$ & $\geq 50$ & $\mathrm{~N}$ & $55.8 \pm 9.1$ & $\mathrm{~N}$ & $6.2 \pm 1.8$ & Y & $\geq 30$ & $\mathrm{~N}$ \\
\hline 2 & $45.7 \pm 1.3$ & $45.5 \pm 3.8$ & $52.7 \pm 7.1$ & $\geq 50$ & $\mathrm{~N}$ & $50.7 \pm 7.1$ & $\mathrm{~N}$ & $4.8 \pm 0.1$ & $\mathrm{Y}$ & $\geq 20$ & $\mathrm{~N}$ \\
\hline 3 & $88.8 \pm 8.8$ & $95.4 \pm 9.2$ & $66.1 \pm 7.2$ & $\geq 75$ & $\mathrm{~N}$ & $54.9 \pm 7.6$ & $\mathrm{~N}$ & $7.1 \pm 3.2$ & Y & $\mathrm{N}$ & $\mathrm{N}$ \\
\hline 4 & $>200$ & $>200$ & $>200$ & $\mathrm{~N}$ & $\mathrm{~N}$ & $>200$ & $\mathrm{~N}$ & $31.2 \pm 10.5$ & $\mathrm{~N}$ & $\mathrm{~N}$ & $\mathrm{~N}$ \\
\hline 5 & $>200$ & $>200$ & $>200$ & $\geq 150$ & $\mathrm{~N}$ & $161.5 \pm 15.2$ & $\geq 200$ & $20.6 \pm 5.9$ & $\mathrm{~N}$ & $\geq 30$ & $\mathrm{~N}$ \\
\hline 6 & $69.6 \pm 1.8$ & $67.0 \pm 4.7$ & $66.3 \pm 4.9$ & $\geq 75$ & $\geq 125$ & $52.0 \pm 9.3$ & $\mathrm{~N}$ & $4.7 \pm 1.1$ & $\mathrm{~N}$ & $\geq 30$ & $\mathrm{~N}$ \\
\hline 7 & $78.0 \pm 5.6$ & $78.2 \pm 4.4$ & $60.0 \pm 8.3$ & $\geq 100$ & $\geq 125$ & $56.1 \pm 8.2$ & $\mathrm{~N}$ & $4.2 \pm 1.0$ & $\mathrm{~N}$ & $\geq 30$ & $\mathrm{~N}$ \\
\hline 8 & $83.1 \pm 3.7$ & $88.8 \pm 10.5$ & $80.8 \pm 3.3$ & $\geq 125$ & $\geq 125$ & $155.8 \pm 15.7$ & $\geq 100$ & $8.1 \pm 2.3$ & Y & $\geq 10$ & $\mathrm{~N}$ \\
\hline 9 & $55.4 \pm 6.7$ & $52.3 \pm 4.8$ & $57.3 \pm 9.2$ & $\geq 75$ & $\geq 125$ & $49.0 \pm 11.8$ & $\mathrm{~N}$ & $5.6 \pm 1.1$ & Y & $\geq 30$ & $\mathrm{~N}$ \\
\hline 10 & $51.5 \pm 9.6$ & $55.9 \pm 12.0$ & $61.2 \pm 7.7$ & $\geq 75$ & $\geq 200$ & $57.9 \pm 7.8$ & $\mathrm{~N}$ & $4.8 \pm 0.5$ & $\mathrm{Y}$ & $\geq 40$ & $\mathrm{~N}$ \\
\hline 11 & $99.7 \pm 5.8$ & $108.0 \pm 19.2$ & $91.8 \pm 5.1$ & $\geq 150$ & $\geq 125$ & $>200$ & $\geq 100$ & $7.4 \pm 1.4$ & $\mathrm{~N}$ & $\geq 40$ & $\mathrm{~N}$ \\
\hline
\end{tabular}

${ }^{1}$ Data represents half maximal inhibitory concentrations $\left(\mathrm{IC}_{50}\right) \pm \mathrm{SD}(\mu \mathrm{M})$ calculated using GraphPad Prism (version 8.2.1, San Diego, CA, USA). ${ }^{2}$ Data represents the lowest observable concentration $(\mu \mathrm{M})$ to cause statistically significant effects. Full datasets shown in Tables S1-S8. Y, detected; N, not detected. 


\section{Discussion}

This study aimed to characterize the in vitro toxicity of the most promising compounds out of a novel range of cytoprotective and mito-protective short-chain quinones (SCQs) [29,30]. Due to the redox activity of the quinone moiety [29], this class of compounds is associated with an inherent risk of producing reactive oxygen species (ROS) [36,37], which could lead to toxicity and cell death at higher concentrations. In addition, the redox activity of quinones can generate false-positive results in many standard viability assays such as MTT and WST-1 [38,39]. Similarly, there is good evidence that redox reactions of SCQs can affect growth factor signalling [23,40] and cell proliferation, which can affect assays that rely on proliferation such as the colony formation assay. Consequently, the current study employed several distinct assays to assess different forms of toxicity including metabolic toxicity, loss of cell membrane integrity, mitochondrial ROS production, long-term toxicity, pyknosis, DNA damage, and transformation potential.

Based on data of related compounds in pre-clinical animal models and patients, the liver is expected to be exposed to the highest concentrations of SCQs [26,41]. In addition, some unrelated compounds have been reported to only show toxicity after metabolic conversion in the liver [42]. Therefore, the present study used a liver-derived cell line to account for this fact. Although HepG2 cells are less metabolically active compared to primary hepatocytes and other cell lines such as C3A or HepaRG, HepG2 cells are widely employed for in vitro toxicity studies due to their high phenotypic stability and unlimited availability for robust and reproducible outcomes [43,44]. It must be acknowledged that this approach cannot exclude tissue-specific toxicities such as neurotoxicity, so our data can only serve as a first approximation to compare the test compounds against reference compounds and against each other. Some test compounds have been successfully used in several animal models of different diseases, in both systemic (oral) and topical (eyedrops) applications over months, without any overt signs of toxicity (unpublished results). This could indicate that this chemical class is generally associated with low toxicity, comparable to the reference compound idebenone; however, this remains to be confirmed experimentally.

When metabolic toxicity was assessed, in general, ATP levels appeared a more sensitive readout compared to the WST-1 assay for all the compounds tested. This could indicate that the interaction of the redox active compounds interfered with the conversion of the WST-1 dye [39] or that the test compounds specifically affect ATP production. Due to this uncertainty, the WST-1 and similar assays should only be used with great caution when testing compounds with confirmed or suspected redox activity. Despite the metabolic limitation of HepG2 cells, our data clearly demonstrate the superior safety profile of the L-phenylalanine derivatives 4 and $\mathbf{5}$ compared to idebenone to enable us to progress these candidates in future studies. It is interesting to note that protein content per well, indicative of cell number, also appeared less sensitive than the measurement of ATP levels. This supports the idea that the test compounds at higher concentrations affect ATP levels in our test system while simultaneously leading to cell loss, presumably by a cell death pathway that involves pyknosis. The subsequent measurement of structural integrity of the cell membrane largely mirrored the toxicity observed with the ATP assay. Surprisingly, the commercial Multi-Tox Fluor assay displayed significantly lower sensitivity when measuring membrane integrity compared to a standard propidium iodide (PI) incorporation assay. The reason for this is not known. While we can only speculate that compared to simple diffusion and binding kinetics of a dye such as PI, the enzymatic conversion of a substrate underlies more restrictive conditions, which might be partially impaired under the specific conditions of our test system. It is interesting to note that the mitochondrial superoxide production did not correlate with the observed ATP data, which suggests that mitochondrial ROS is not responsible for the metabolic toxicity, while the observed acute toxicities were replicated by the colony formation assay that measures long-term toxicity. Overall, the results of the present study consistently demonstrate that only the two $L$-phenylalanine derivatives 4 and $\mathbf{5}$ show comparable or lower levels of toxicity compared to the reference compound idebenone across most endpoints utilized in this study. 
Since most results in this study could be attributed to cell loss, we assessed structural changes in nuclear morphology (pyknosis), which is mostly indicative of apoptotic cell death [45]. Surprisingly, the results of this approach differed significantly from the results of the previous assays. In particular, the significantly lower induction of pyknosis by several test compounds compared to idebenone did not correlate with the previous toxicity assays (Table 2). For some compounds, the measured toxicity did not lead to a significant induction of pyknosis despite profound effects on protein levels, such as the tyramine derivatives 6 and 7 and the L-proline derivative 11. The molecular reason for this obvious discrepancy is unclear at present and is subject to ongoing investigations but could either involve a different form of cell death such as necrosis or a difference in time course. When we assessed the DNA damaging potential of our test compounds, idebenone did not induce any DNA damage, while most test compounds showed a dose-dependent induction of DNA damage at higher concentrations. One exception was the $L$-phenylalanine derivative 4 that consistently showed low or absent toxicity throughout most assays. However, the structurally related L-phenylalaninol derivative 3 [30], also showed no significant induction of DNA damage, which was surprising given the consistent toxicity results from all other assays. Based on the observed DNA damaging activity of some test compounds, their transformation potential was assessed. The reference compound PhIP increased transformation only up to $30 \mu \mathrm{M}$ in our test system, since cytotoxicity at higher concentrations has been reported [46]. In contrast, the clinically used idebenone [47,48] as well as the test compounds also did not appear to promote cellular transformation in this test system, but their toxicities were mirrored in the agar invasion assay in a concentration dependent manner.

Collectively, this study highlights the independence of the toxicity assays used and justifies a panel of assays to detect the different aspects of toxicity of a class of compounds during early drug development. The current study indicates that the carboxylic acid derivatives (i.e., 4 and 11) are significantly less toxic than the corresponding alcohols (i.e., $\mathbf{3}$ and 10, respectively). One possible explanation could be that oxidative metabolites of alcohols could show greater toxicity. However, the reported high metabolic stability of these compounds [30] seems to directly implicate the alcohol function in their increased toxicity in vitro. Although the current study does not allow any predictions towards toxicity in vivo, it is important to relate the observed results to expected in vivo concentrations. At present, achievable plasma or tissue levels for the test compounds are not known. However, for the chemically related reference compound idebenone, the highest achievable plasma concentrations $\left(C_{\max }\right)$ in patients are in the single digit micromolar range [49]. While tissue levels in the central nervous system and retina are in the low nanomolar range [41,50], the highest concentrations were detected in the liver $(\sim 2 \mu \mathrm{M}$ in rats; $\sim 10 \mu \mathrm{M}$ in dogs) [41]. However, these concentrations are only present for short periods of time (minutes to a few hours depending on the organism) due to the high rate of hepatic metabolism [26,50]. While our test compounds show significantly higher metabolic stability compared to idebenone [30], their structural similarity and solubility characteristics could indicate similar $C_{\max }$ values in vivo. For idebenone, detailed toxicity data is available from a large range of patients $[18,26,27,51]$. Despite the in vitro toxicity observed in the present study for concentrations above $5 \mu \mathrm{M}$ (Table 2 and Tables S1-S8), idebenone is extremely well tolerated up to concentrations of $2250 \mathrm{mg} /$ patient/day with the most common adverse events described as reversible intestinal disturbances [26]. Hence, the observed toxicities for the test compounds in this study, even if higher than idebenone, cannot be interpreted as evidence for systemic toxicities at therapeutic doses. Nevertheless, the increased in vitro metabolic stability of our test compounds compared to idebenone could increase area under the curve (AUC) values [30] while altered chemical structures and solubilities could influence ADME characteristics. This highlights that the present study explored the concentrations from which toxicity can be expected and requires future pharmacokinetic studies of selected compounds in vivo to establish their safety margins.

Based on the current data and unpublished and ongoing studies, future studies will investigate the suitability of the most promising compounds to counteract mitochondrial dysfunctioninduced pathologies. 


\section{Materials and Methods}

\subsection{Chemicals and Reagents}

Idebenone was provided by Santhera Pharmaceuticals (Pratteln, Basel-Landschaft, Switzerland) as a reference compound. The novel naphthoquinone derivatives 1-11 were synthesized as described previously [29]. Dimethylsulfoxide (DMSO), Dulbecco Modified Eagle Medium (DMEM, D5523), sodium bicarbonate $\left(\mathrm{NaHCO}_{3}\right)$, 2-[4-(2-hydroxyethyl)piperazin-1-yl]ethanesulfonic acid (HEPES), 1,4-dithiothreitol (DTT), magnesium chloride $\left(\mathrm{MgCl}_{2}\right)$, bovine serum albumin (BSA), Triton X-100, paraformaldehyde (PFA), Tween-20, rat tail collagen, sodium hydroxide $(\mathrm{NaOH})$, propidium iodide (PI), poly-L-lysine, menadione, $4^{\prime}$,6-diamidino-2-phenylindole (DAPI), noble agar, and resazurin sodium salt were purchased from Sigma-Aldrich (Ryde, NSW, Australia). Trypsin, ethylenediaminetetraacetic acid (EDTA), phosphate-buffered saline (PBS) tablets, Hanks Balanced Salt Solution (HBSS), MitoSOX Red, Hoechst 33342, Coomassie Brilliant Blue, and goat anti-mouse Alexa Fluor 488 secondary antibody (A-11029) were obtained from Thermo Fisher Scientific (Scoresby, VIC, Australia). Foetal bovine serum (FBS) was obtained from SAFC Biosciences (Brooklyn, VIC, Australia). WST-1 Assay Kit and 2-amino-1-methyl-6-phenylimidazo[4-b]pyridine (PhIP) were obtained from Cayman Chemical (Redfern, NSW, Australia). DC Protein Assay Kit was obtained from Bio-Rad Laboratories (Gladesville, NSW, Australia). D-luciferin, luciferase, and MultiTox-Fluor Multiplex Cytotoxicity Assay Kit were obtained from Promega (Alexandria, NSW, Australia). Mouse monoclonal anti-phospho-Histone $\mathrm{H}_{2} \mathrm{AX}$ (Ser139) antibody (JBW301) was obtained from Merck (Kilsyth, VIC, Australia). Methanol and acetic acid were obtained from VWR (Tingalpa, QLD, Australia). Cell culture plastics were obtained from Corning (Mulgrave, VIC, Australia), if not stated otherwise.

For all assays, stock solutions (100 mM in DMSO) of reference and test compounds were prepared as single use aliquots and stored at $-20{ }^{\circ} \mathrm{C}$ until used. DMEM was prepared according to the manufacturer's instructions, sterilized by filtration using $0.22 \mu \mathrm{m}$ bottle top filters, supplemented with FBS $(10 \%), \mathrm{NaHCO}_{3}(3.7 \mathrm{~g} / \mathrm{L})$, and stored at $4{ }^{\circ} \mathrm{C}$.

\subsection{Cell Culture}

Cryopreserved HepG2 cells (HB-8065, ATCC, Noble Park North, VIC, Australia) were passaged after thawing for at least 2-3 weeks to reach steady cumulative growth rates before being used for the experiments. The cells were routinely cultured in $5 \mathrm{~mL}$ DMEM $\left(95 \%\right.$ humidified air, $5 \% \mathrm{CO}_{2}$, $\left.37^{\circ} \mathrm{C}\right)$ in cell culture flasks $\left(25 \mathrm{~cm}^{2}, 0.2 \mu \mathrm{m}\right.$ vent cap). The cells were passaged twice weekly when reaching $75 \%$ confluency. Cell suspensions were generated by trypsinization $(1 \times$ wash with $5 \mathrm{~mL}$ PBS, $1 \times 0.5 \mathrm{~mL}$ EDTA $(0.5 \mathrm{mM}, \mathrm{pH} 8), 1 \times 0.5 \mathrm{~mL}$ trypsin $(0.25 \%, 3.5 \mathrm{~min})$, and seeded into new T25 flasks at $8 \times 10^{4} \mathrm{cells} / \mathrm{cm}^{2}$.

\subsection{Multiplex Detection of $N A D(P) H, A T P$, and Protein Levels}

The multiplex detection of NAD(P)H synthesis (absorption, $450 \mathrm{~nm}$ ), ATP (luminescence) and protein levels (absorption, $750 \mathrm{~nm}$ ) from individual wells was used to increase throughput and quality of results. No statistically significant differences were observed over a range of concentrations with or without $\mathrm{NAD}(\mathrm{P}) \mathrm{H}$ measurement prior to the quantitation of ATP and protein content from cell lysates (Figure S1). Briefly, $2 \times 10^{4}$ cells were seeded in $100 \mu \mathrm{L}$ DMEM per well in transparent 96-well plates and left to adhere overnight. Subsequently, cells were treated with test compounds for $24 \mathrm{~h}(0-200 \mu \mathrm{M}$ in $25 \mu \mathrm{L}$ DMEM). After incubation with $5 \mu \mathrm{L}$ WST-1 reagent for $1 \mathrm{~h}$, absorption was measured using a plate reader (Multiskan Go, Thermo Fisher Scientific, Scoresby, VIC, Australia). After media removal, cells were washed twice with $110 \mu \mathrm{L}$ PBS and permeabilized for $10 \mathrm{~min}(0.5 \%$ Triton X-100/PBS, $40 \mu \mathrm{L})$ at room temperature. Cell lysates $(10 \mu \mathrm{L})$ were mixed with reaction buffer $(300 \mu \mathrm{M}$ D-luciferin, $5 \mu \mathrm{g} / \mathrm{mL}$ luciferase, $25 \mathrm{mM}$ HEPES, $75 \mu \mathrm{M}$ DTT, $6.25 \mathrm{mM} \mathrm{MgCl}_{2}, 625 \mu \mathrm{M}$ EDTA, $1 \mathrm{mg} / \mathrm{mL}$ BSA in PBS, pH 7.4; $90 \mu \mathrm{L}$ ) in white 96-well plates, followed by immediate measurement of luminescence using a plate reader (Fluoroskan Ascent, Thermo Fisher Scientific, Scoresby, VIC, Australia). Lastly, 
protein contents from cell lysates $(5 \mu \mathrm{L})$ were quantified using the DC Protein Assay as recommended by the manufacturer. Absorption and relative luminescence units (RLU) were standardized on the non-treated control cells $(100 \%)$. A standard curve using BSA $(0-2 \mathrm{mg} / \mathrm{mL})$ was used for protein quantitation, and protein levels were standardized on the non-treated control (100\%). Data was expressed as mean \pm standard error of the mean (SEM) from independent experiments with 6 parallel wells per experiment.

\subsection{Propidium Iodide Incorporation}

Cell membrane integrity was assessed using the non-cell membrane permeable dye propidium iodide (PI). For this purpose, $1 \times 10^{4}$ cells were seeded in $100 \mu \mathrm{L}$ DMEM per well in 384-well plates (781091, $\mu$ Clear, Greiner, Ryde, NSW, Australia) and left to adhere overnight. Subsequently, the cells were treated with test compounds for $24 \mathrm{~h}(0-200 \mu \mathrm{M}$ in $50 \mu \mathrm{L}$ DMEM). After media removal, the cells were stained with PI solution for $30 \mathrm{~min}(5 \mu \mathrm{M}$ in $50 \mu \mathrm{L}$ PBS), before PI fluorescence (Ex/Em $545 / 600 \mathrm{~nm}$ ) was quantified using a plate reader (Fluoroskan Ascent, Thermo Fisher Scientific, Scoresby, VIC, Australia). RFUs were standardized on the non-treated control and expressed as fold-induction. Data represented the mean \pm SEM from 3 independent experiments with 4 parallel wells per experiment.

\subsection{Multi-Tox Fluor Kit}

Following exposure to test compounds, two different toxicity parameters were measured using the MultiTox-Fluor Kit according to the manufacturer's instructions. For this purpose, $5 \times 10^{3}$ cells were seeded in $100 \mu \mathrm{L}$ DMEM per well in black 384-well plates (781091, $\mu$ Clear, Greiner, Ryde, NSW, Australia) and left to adhere overnight. Subsequently, the cells were treated with test compounds for $24 \mathrm{~h}(0-200 \mu \mathrm{M}$ in $25 \mu \mathrm{L}$ DMEM). After incubation with the protease substrate mix for $1 \mathrm{~h}$ (permeable GF-AFC and non-permeable bis-AAF-R110, $25 \mu \mathrm{L}$ ), fluorescence for GF-AFC (Ex/Em 400/505 nm) and bis-AAF-R110 (Ex/Em 485/520 nm) were measured, respectively, using a multimode plate reader (Tecan Spark 20M, Tecan, Port Melbourne, VIC, Australia). RFUs were standardized on the non-treated control $(100 \%)$ and expressed as mean \pm SEM from 3 independent experiments with 3 parallel wells per experiment.

\subsection{MitoSOX}

To measure mitochondrial superoxide production, 384-well plates (781091, $\mu$ Clear, Greiner, Ryde, NSW, Australia) were coated with poly-L-lysine for $45 \mathrm{~min}$ (1:20 in HBSS, pH 7.4, $50 \mu \mathrm{L} /$ well) before $9 \times 10^{3}$ cells were seeded in $50 \mu \mathrm{L}$ DMEM per well, left to adhere for $3 \mathrm{~h}$, and loaded with MitoSOX Red $(1 \mu \mathrm{M})$ and Hoechst $33342(2 \mu \mathrm{g} / \mathrm{mL}$ in HBSS $+1 \%$ BSA, $30 \mu \mathrm{L} /$ well) for $30 \mathrm{~min}$ (Figure S2). After treatment with test compounds for $30 \mathrm{~min}(0-200 \mu \mathrm{M}$ in HBSS $+1 \% \mathrm{BSA}, 50 \mu \mathrm{L} /$ well), fluorescence (Ex/Em 355/600 nm) was quantified using a plate reader (Fluoroskan Ascent, Thermo Fisher Scientific, Scoresby, VIC, Australia). Antimycin A was used as a positive control [31]. RFUs were standardized on the non-treated control and expressed as fold-induction. Data represented the mean \pm SEM from 3 independent experiments with 8 eight parallel wells per experiment.

\subsection{Colony Formation Assay}

$2.5 \times 10^{3}$ cells were seeded in $2 \mathrm{~mL}$ DMEM per well in 6-well plates and left to adhere overnight. Subsequently, cells were treated with test compounds for 14 days $(0-100 \mu \mathrm{M})$. After media removal, the colonies were fixed for $10 \mathrm{~min}(4 \% \mathrm{PFA} / \mathrm{PBS}, 2 \mathrm{~mL} /$ well), stained for $10 \mathrm{~min}$ ( $1 \%$ Coomassie Brilliant Blue in $50 \%$ methanol and $10 \%$ acetic acid, $2 \mathrm{~mL} /$ well), before the colonies ( $>50$ cells) were counted under a light microscope. Colony numbers were standardized on the non-treated control $(100 \%)$ and expressed as mean \pm SEM from 3 independent experiments with 4 four parallel wells per experiment. 


\subsection{Assessment of Changes in Nuclear Morphology}

To quantitate nuclear morphology, 384-well plates (781091, $\mu$ Clear, Greiner, Ryde, NSW, Australia) were coated with rat tail collagen for $45 \mathrm{~min}$ (1:20 in HBSS, pH 7.4, $50 \mu \mathrm{L} /$ well) before $1 \times 10^{4}$ cells were seeded in $100 \mu \mathrm{L}$ DMEM per well and left to adhere overnight. After treatment with test compounds for $24 \mathrm{~h}(100 \mu \mathrm{M}$ in $50 \mu \mathrm{L}$ HBSS), fixation for $10 \mathrm{~min}(4 \% \mathrm{PFA} / \mathrm{PBS}, 50 \mu \mathrm{L} /$ well $)$ and permeabilization for $10 \mathrm{~min}(0.5 \%$ Triton X-100/PBS, $50 \mu \mathrm{L} /$ well), the cells were stained with DAPI for $2 \mathrm{~min}$ (1:10,000 in 0.1\% Tween-20/PBS, $15 \mu \mathrm{L} /$ well). After washing three times for $5 \mathrm{~min}$ (PBST, $50 \mu \mathrm{L} /$ well), cells were stored in PBS $(50 \mu \mathrm{L})$ for high content imaging using an IN Cell 2200 analyser (10 $\times$ magnification, GE Healthcare, Rydalmere, NSW, Australia). Morphological changes (area and intensity) were automatically quantified for each individual nucleus. Images acquired from 4 wells with 2 images each were automatically analysed using IN Carta image analysis software (GE Healthcare, Rydalmere, NSW, Australia). Nuclear intensity was standardized on the average intensity of non-treated control nuclei and expressed as fold-change. Data represented the mean \pm SEM of quadruplicates and $\sim 1000$ cells were analysed per treatment.

\subsection{Assessment of DNA Damage}

To assess DNA damage, $5 \times 10^{3}$ cells were seeded in $100 \mu \mathrm{L}$ serum-free DMEM per well in 384-well plates (781091, $\mu$ Clear, Greiner, Ryde, NSW, Australia) pre-coated with rat tail collagen as described above and left to adhere overnight. The cells were treated with test compounds for $4 \mathrm{~h}(0-40 \mu \mathrm{M}$ in $100 \mu \mathrm{L} \mathrm{HBSS} /$ well $)$ while menadione was used as a positive control [32]. After fixation $(50 \mu \mathrm{L})$ and permeabilization $(50 \mu \mathrm{L})$ as described above, unspecific antibody binding was blocked for $1 \mathrm{~h}$ ( $5 \%$ FBS $+5 \%$ BSA in PBS, $50 \mu \mathrm{L} /$ well) before the samples were exposed to mouse monoclonal anti-phospho-Histone $\mathrm{H}_{2} \mathrm{AX}$ (Ser139) antibody overnight (1:1000 in blocking buffer, $15 \mu \mathrm{L} /$ well). After exposure to goat anti-mouse Alexa Fluor 488 secondary antibody for $1 \mathrm{~h}(1: 10,000$ in PBST, $15 \mu \mathrm{L} /$ well), nuclei were counterstained using DAPI and stored for imaging and analysis as described above. The average numbers of $\gamma-\mathrm{H}_{2} \mathrm{AX}$-positive cells were automatically quantified for all acquired images using IN Carta image analysis software (GE Healthcare, Rydalmere, NSW, Australia). Results were standardized on the non-treated control and expressed as fold-change. Data represented the mean \pm SEM of quadruplicate images from 3 independent assays. At least 1000 cells were analysed per treatment.

\subsection{Agar Invasion Assay}

To further investigate if the test compounds can induce mutations in cells at previously tested concentrations $(10-40 \mu \mathrm{M})$, the agar invasion assay in 384-well format (781091, $\mu$ Clear, Greiner, Ryde, NSW, Australia) was performed as previously described [33]. PhIP was used as a positive control [35]. Cell numbers and incubation times were optimized for PhIP and used for all the test compounds. Two hundred cells were seeded in $50 \mu \mathrm{L}$ DMEM $(0.4 \%$ agar supplemented) per well in 384-well plates pre-coated with solidified agar $(0.6 \%, 10 \mu \mathrm{L})$. The plates were left to solidify for $1 \mathrm{~h}$ at room temperature and incubated overnight at $37^{\circ} \mathrm{C}$ before cells were treated for 21 days with reference and test compounds (10-40 $\mu \mathrm{M}$ in $15 \mu \mathrm{L}$ DMEM/well). Subsequently, the cells were stained with resazurin for $4 \mathrm{~h}(440 \mu \mathrm{M}$ in $7 \mu \mathrm{L}$ PBS/well) [34] before fluorescence (Ex/Em 545/600 nm) was quantified using a plate reader (Fluoroskan Ascent, Thermo Fisher Scientific, Scoresby, VIC, Australia). RFUs were standardized on the non-treated control and expressed as fold-induction. Data represented the mean \pm SEM from 3 independent experiments with 3 parallel wells per experiment.

\subsection{Statistical Analysis}

Using GraphPad Prism (version 8.2.1, San Diego, CA, USA), one- or two-way ANOVA followed by Dunnett's multiple comparison post-test was performed to compare between compounds or concentrations: ${ }^{* * *} p<0.001,{ }^{* *} p<0.002,{ }^{*} p<0.033$, otherwise non-significant; non-linear regressions 
were generated and half maximal inhibitory concentrations $\left(\mathrm{IC}_{50}\right)$ were automatically calculated by the software.

\section{Conclusions}

This study characterized the in vitro toxicity of the most promising cytoprotective and mito-protective short-chain naphthoquinones [29,30]. The multiplex detection of compatible assays described in this study provides a convenient, cost-effective, and rapid approach to increase throughput. Overall, the test compounds, with some exceptions, showed largely comparable results between different assays. However, standard assays/dyes appeared to be associated with significantly higher sensitivity compared to commercially available kits. Compared to the other test compounds, the L-phenylalanine derivative 4 showed the most promising safety profile, with lower metabolic toxicity, lower effects on membrane integrity, lower long-term toxicity, as well as an absence of mitochondrial toxicity, pyknosis, DNA damage, or transformation potential. Our results highlight the importance of using a set of independent assays to assess distinct toxicity profiles to characterize a class of compounds. Importantly, this study increased our understanding of the comparative toxicities of the range of test compounds and supports the development of the most promising short-chain naphthoquinone(s) towards their clinical use.

Supplementary Materials: The following are available online at http://www.mdpi.com/1424-8247/13/8/184/s1, Figure S1: Validation of multiplex detection of $\mathrm{NAD}(\mathrm{P}) \mathrm{H}, \mathrm{ATP}$ and Protein Levels, Figure S2: Exemplary images of MitoSOX localization in HepG2 cells used to measure mitochondrial superoxide production, Table S1: Effect of test compounds on WST-1 absorption, Table S2: Effect of test compounds on ATP levels, Table S3: Effect of test compounds on protein levels, Table S4: Effect of test compounds on propidium iodide (PI) incorporation, Table S5: Effect of test compounds on necrotic-cell protease activity, Table S6: Effect of test compounds on viable-cell protease activity, Table S7: Effect of test compounds on mitochondrial superoxide production, Table S8: Effect of test compounds on colony formation.

Author Contributions: Conceptualization, investigation and writing, Z.F., J.A.S. and N.G.; methodology, validation and formal analysis, Z.F., M.S., M.C., I.A. and N.G.; data curation, Z.F. and M.S.; visualization, Z.F.; resources, A.D., K.L.W., R.C., I.A., J.A.S. and N.G.; supervision, funding acquisition and project administration, J.A.S. and N.G. All authors have read and agreed to the published version of the manuscript.

Funding: This research was partially funded by the National Foundation for Medical Research and Innovation (NFMRI), Australia.

Acknowledgments: Z.F. is thankful to the University of Tasmania for receiving a Tasmanian Graduate Research Scholarship. The authors would like to thank Santhera Pharmaceuticals for providing idebenone as the reference compound.

Conflicts of Interest: N.G. acts as scientific consultant to Santhera Pharmaceuticals, which develops idebenone for neuromuscular disorders and mitochondrial diseases.

\section{References}

1. Stepanova, A.; Magrané, J. Mitochondrial dysfunction in neurons in Friedreich's ataxia. Mol. Cell. Neurosci. 2020, 102, 103419. [CrossRef] [PubMed]

2. Kato, H.; Han, X.; Yamaza, H.; Masuda, K.; Hirofuji, Y.; Sato, H.; Pham, T.T.M.; Taguchi, T.; Nonaka, K. Direct effects of mitochondrial dysfunction on poor bone health in Leigh syndrome. Biochem. Biophys. Res. Commun. 2017, 493, 207-212. [CrossRef] [PubMed]

3. Frey, S.; Geffroy, G.; Desquiret-Dumas, V.; Gueguen, N.; Bris, C.; Belal, S.; Amati-Bonneau, P.; Chevrollier, A.; Barth, M.; Henrion, D.; et al. The addition of ketone bodies alleviates mitochondrial dysfunction by restoring complex I assembly in a MELAS cellular model. Biochem. Biophys. Acta Mol. Basis Dis. 2017, 1863, $284-291$. [CrossRef] [PubMed]

4. Tabebi, M.; Charfi, N.; Kallabi, F.; Alila-Fersi, O.; Mahmoud, A.B.; Tlili, A.; Keskes-Ammar, L.; Kamoun, H.; Abid, M.; Mnif, M.; et al. Whole mitochondrial genome screening of a family with maternally inherited diabetes and deafness (MIDD) associated with retinopathy: A putative haplotype associated to MIDD and a novel MT-CO2 m.8241T>G mutation. J. Diabetes Complicat. 2017, 31, 253-259. [CrossRef] [PubMed] 
5. Sharma, L.K.; Tiwari, M.; Rai, N.K.; Bai, Y. Mitophagy activation repairs Leber's hereditary optic neuropathy-associated mitochondrial dysfunction and improves cell survival. Hum. Mol. Genet. 2019, 28, 422-433. [CrossRef] [PubMed]

6. Romagnoli, M.; La Morgia, C.; Carbonelli, M.; Di Vito, L.; Amore, G.; Zenesini, C.; Cascavilla, M.L.; Barboni, P.; Carelli, V. Idebenone increases chance of stabilization/recovery of visual acuity in OPA1-dominant optic atrophy. Ann. Clin. Transl. Neurol. 2020. [CrossRef]

7. Xiong, Q.; Ru, Q.; Chen, L.; Tian, X.; Li, C. Mitochondrial dysfunction and inflammatory response in the cytotoxicity of NR8383 macrophages induced by fine particulate matter. Environ. Toxicol. Pharmacol. 2017, 55, 1-7. [CrossRef]

8. Picard, M.; Wallace, D.C.; Burelle, Y. The rise of mitochondria in medicine. Mitochondrion 2016, 30, $105-116$. [CrossRef]

9. Kozin, M.S.; Kulakova, O.G.; Favorova, O.O. Involvement of Mitochondria in Neurodegeneration in Multiple Sclerosis. Biochemistry (Moscow) 2018, 83, 813-830. [CrossRef]

10. Rigotto, G.; Basso, E. Mitochondrial Dysfunctions: A Thread Sewing Together Alzheimer's Disease, Diabetes, and Obesity. Oxid. Med. Cell. Longev. 2019, 2019, 7210892. [CrossRef]

11. Gueven, N.; Woolley, K.; Smith, J. Border between natural product and drug: Comparison of the related benzoquinones idebenone and coenzyme Q10. Redox Biol. 2015, 4, 289-295. [CrossRef] [PubMed]

12. Erb, M.; Hoffmann-Enger, B.; Deppe, H.; Soeberdt, M.; Haefeli, R.H.; Rummey, C.; Feurer, A.; Gueven, N. Features of idebenone and related short-chain quinones that rescue ATP levels under conditions of impaired mitochondrial complex I. PLoS ONE 2012, 7, e36153. [CrossRef] [PubMed]

13. Haefeli, R.H.; Erb, M.; Gemperli, A.C.; Robay, D.; Fruh, I.C.; Anklin, C.; Dallmann, R.; Gueven, N. NQO1-dependent redox cycling of idebenone: Effects on cellular redox potential and energy levels. PLOS ONE 2011, 6, e17963. [CrossRef]

14. Sullivan, K.; Freeman, M.; Shaw, J.; Gooch, C.; Huang, Y.; Klein, M.; Miller, G.; Zesiewicz, T. EPI-743 for Friedreichs Ataxia Patients with Point Mutations (P5.388). Neurology 2016, 86, P5.388.

15. Martinelli, D.; Catteruccia, M.; Piemonte, F.; Pastore, A.; Tozzi, G.; Dionisi-Vici, C.; Pontrelli, G.; Corsetti, T.; Livadiotti, S.; Kheifets, V.; et al. EPI-743 reverses the progression of the pediatric mitochondrial disease-genetically defined Leigh Syndrome. Mol. Genet. Metab. 2012, 107, 383-388. [CrossRef]

16. Janssen, M.C.H.; Koene, S.; de Laat, P.; Hemelaar, P.; Pickkers, P.; Spaans, E.; Beukema, R.; Beyrath, J.; Groothuis, J.; Verhaak, C.; et al. The KHENERGY Study: Safety and Efficacy of KH176 in Mitochondrial m.3243A>G Spectrum Disorders. Clin. Pharmacol. Ther. 2019, 105, 101-111. [CrossRef]

17. Koene, S.; Spaans, E.; Van Bortel, L.; Van Lancker, G.; Delafontaine, B.; Badilini, F.; Beyrath, J.; Smeitink, J. KH176 under development for rare mitochondrial disease: A first in man randomized controlled clinical trial in healthy male volunteers. Orphanet J. Rare Dis. 2017, 12, 163. [CrossRef]

18. Klopstock, T.; Yu-Wai-Man, P.; Dimitriadis, K.; Rouleau, J.; Heck, S.; Bailie, M.; Atawan, A.; Chattopadhyay, S.; Schubert, M.; Garip, A.; et al. A randomized placebo-controlled trial of idebenone in Leber's hereditary optic neuropathy. Brain 2011, 134, 2677-2686. [CrossRef]

19. Rudolph, G.; Dimitriadis, K.; Buchner, B.; Heck, S.; Al-Tamami, J.; Seidensticker, F.; Rummey, C.; Leinonen, M.; Meier, T.; Klopstock, T. Effects of idebenone on color vision in patients with leber hereditary optic neuropathy. J. Neuro-ophthalmol. 2013, 33, 30-36. [CrossRef] [PubMed]

20. Klopstock, T.; Metz, G.; Yu-Wai-Man, P.; Buchner, B.; Gallenmuller, C.; Bailie, M.; Nwali, N.; Griffiths, P.G.; von Livonius, B.; Reznicek, L.; et al. Persistence of the treatment effect of idebenone in Leber's hereditary optic neuropathy. Brain 2013, 136, e230. [CrossRef]

21. Barboni, P.; Valentino, M.L.; La Morgia, C.; Carbonelli, M.; Savini, G.; De Negri, A.; Simonelli, F.; Sadun, F.; Caporali, L.; Maresca, A.; et al. Idebenone treatment in patients with OPA1-mutant dominant optic atrophy. Brain 2013, 136, e231. [CrossRef] [PubMed]

22. Lagedrost, S.J.; Sutton, M.S.; Cohen, M.S.; Satou, G.M.; Kaufman, B.D.; Perlman, S.L.; Rummey, C.; Meier, T.; Lynch, D.R. Idebenone in Friedreich ataxia cardiomyopathy-results from a 6-month phase III study (IONIA). Am. Heart J. 2011, 161, 639-645.e1. [CrossRef] [PubMed]

23. Tomilov, A.; Allen, S.; Hui, C.K.; Bettaieb, A.; Cortopassi, G. Idebenone is a cytoprotective insulin sensitizer whose mechanism is Shc inhibition. Pharmacol. Res. 2018, 137, 89-103. [CrossRef] [PubMed] 
24. Tiefenbach, J.; Magomedova, L.; Liu, J.; Reunov, A.A.; Tsai, R.; Eappen, N.S.; Jockusch, R.A.; Nislow, C.; Cummins, C.L.; Krause, H.M. Idebenone and coenzyme Q10 are novel PPARalpha/gamma ligands, with potential for treatment of fatty liver diseases. Dis. Model Mech. 2018, 11. [CrossRef]

25. Lei, D.; Shao, Z.; Zhou, X.; Yuan, H. Synergistic neuroprotective effect of rasagiline and idebenone against retinal ischemia-reperfusion injury via the Lin28-let-7-Dicer pathway. Oncotarget 2018, 9, 12137-12153. [CrossRef]

26. Becker, C.; Bray-French, K.; Drewe, J. Pharmacokinetic evaluation of idebenone. Expert Opin. Drug Metab. Toxicol. 2010, 6, 1437-1444. [CrossRef]

27. Buyse, G.M.; Voit, T.; Schara, U.; Straathof, C.S.; D’Angelo, M.G.; Bernert, G.; Cuisset, J.M.; Finkel, R.S.; Goemans, N.; Rummey, C.; et al. Treatment effect of idebenone on inspiratory function in patients with Duchenne muscular dystrophy. Pediat. Pulmonol. 2017, 52, 508-515. [CrossRef]

28. Bodmer, M.; Vankan, P.; Dreier, M.; Kutz, K.W.; Drewe, J. Pharmacokinetics and metabolism of idebenone in healthy male subjects. Eur. J. Clin. Pharmacol. 2009, 65, 493-501. [CrossRef]

29. Woolley, K.L.; Nadikudi, M.; Koupaei, M.N.; Corban, M.; McCartney, P.; Bissember, A.C.; Lewis, T.W.; Gueven, N.; Smith, J.A. Amide linked redox-active naphthoquinones for the treatment of mitochondrial dysfunction. MedChemComm 2019, 10, 399-412. [CrossRef]

30. Feng, Z.; Smith, J.A.; Gueven, N.; Quirino, J.P. Metabolic Stability of New Mito-Protective Short-Chain Naphthoquinones. Pharmaceuticals (Basel) 2020, 13, 29. [CrossRef]

31. Quinlan, C.L.; Gerencser, A.A.; Treberg, J.R.; Brand, M.D. The mechanism of superoxide production by the antimycin-inhibited mitochondrial Q-cycle. J. Biol. Chem. 2011, 286, 31361-31372. [CrossRef] [PubMed]

32. Luukkonen, J.; Liimatainen, A.; Hoyto, A.; Juutilainen, J.; Naarala, J. Pre-exposure to $50 \mathrm{~Hz}$ magnetic fields modifies menadione-induced genotoxic effects in human SH-SY5Y neuroblastoma cells. PLoS ONE 2011, 6, e18021. [CrossRef] [PubMed]

33. Anderson, S.N.; Towne, D.L.; Burns, D.J.; Warrior, U. A high-throughput soft agar assay for identification of anticancer compound. J. Biomol. Screen. 2007, 12, 938-945. [CrossRef] [PubMed]

34. Uzarski, J.S.; DiVito, M.D.; Wertheim, J.A.; Miller, W.M. Essential design considerations for the resazurin reduction assay to noninvasively quantify cell expansion within perfused extracellular matrix scaffolds. Biomaterials 2017, 129, 163-175. [CrossRef]

35. Koch, W.H.; Wu, R.W.; Cebula, T.A.; Felton, J.S. Specificity of base substitution mutations induced by the dietary carcinogens 2-amino-1-methyl-6-phenylimidazo[4,5-b]pyridine (PhlP) and 2-amino-3-methylimidazo[4,5-f]quinoline (IQ) in Salmonella. Environ. Mol. Mutagenes. 1998, 31, 327-332. [CrossRef]

36. Kim, Y.J.; Shin, Y.K.; Sohn, D.S.; Lee, C.S. Menadione induces the formation of reactive oxygen species and depletion of GSH-mediated apoptosis and inhibits the FAK-mediated cell invasion. Naunyn Schmiedeberg's Arch. Pharmacol. 2014, 387, 799-809. [CrossRef]

37. de Carvalho Scharf Santana, N.; Lima, N.A.; Desoti, V.C.; Bidoia, D.L.; de Souza Bonfim Mendonca, P.; Ratti, B.A.; Nakamura, T.U.; Nakamura, C.V.; Consolaro, M.E.; Ximenes, V.F.; et al. Vitamin K3 induces antiproliferative effect in cervical epithelial cells transformed by HPV 16 (SiHa cells) through the increase in reactive oxygen species production. Arch. Gynecol. Obstet. 2016, 294, 797-804. [CrossRef]

38. Tan, A.S.; Berridge, M.V. Differential effects of redox-cycling and arylating quinones on trans-plasma membrane electron transport. BioFactors 2008, 34, 183-190. [CrossRef]

39. Tan, A.S.; Berridge, M.V. Evidence for NAD(P)H: Quinone oxidoreductase 1 (NQO1)-mediated quinone-dependent redox cycling via plasma membrane electron transport: A sensitive cellular assay for NQO1. Free Radic. Biol. Med. 2010, 48, 421-429. [CrossRef]

40. Dustin, C.M.; Heppner, D.E.; Lin, M.J.; van der Vliet, A. Redox regulation of tyrosine kinase signalling: More than meets the eye. J. Biochem. 2020, 167, 151-163. [CrossRef]

41. Torii, H.; Yoshida, K.; Kobayashi, T.; Tsukamoto, T.; Tanayama, S. Disposition of idebenone (CV-2619), a new cerebral metabolism improving agent, in rats and dogs. J. Pharmacobiodyn. 1985, 8, 457-467. [CrossRef] [PubMed]

42. Wang, Y.K.; Yang, X.N.; Zhu, X.; Xiao, X.R.; Yang, X.W.; Qin, H.B.; Gonzalez, F.J.; Li, F. Role of Metabolic Activation in Elemicin-Induced Cellular Toxicity. J. Agric. Food Chem. 2019, 67, 8243-8252. [CrossRef] [PubMed] 
43. Sussman, N.L.; Kelly, J.H. Artificial liver: A forthcoming attraction. Hepatology 1993, 17, 1163-1164. [CrossRef] [PubMed]

44. Yokoyama, Y.; Sasaki, Y.; Terasaki, N.; Kawataki, T.; Takekawa, K.; Iwase, Y.; Shimizu, T.; Sanoh, S.; Ohta, S. Comparison of Drug Metabolism and Its Related Hepatotoxic Effects in HepaRG, Cryopreserved Human Hepatocytes, and HepG2 Cell Cultures. Biol. Pharm. Bull. 2018, 41, 722-732. [CrossRef] [PubMed]

45. Kroemer, G.; Galluzzi, L.; Vandenabeele, P.; Abrams, J.; Alnemri, E.S.; Baehrecke, E.H.; Blagosklonny, M.V.; El-Deiry, W.S.; Golstein, P.; Green, D.R.; et al. Classification of cell death: Recommendations of the Nomenclature Committee on Cell Death 2009. Cell Death Differ. 2009, 16, 3-11. [CrossRef]

46. Poudel, B.K.; Choi, J.; Park, J.H.; Doh, K.O.; Byeon, J.H. In vitro exposure of simulated meat-cooking fumes to assess adverse biological effects. Sci. Rep. 2017, 7, 10841. [CrossRef]

47. Lingetti, M.; Porfido, F.A.; Ciarimboli, M.; Oliviero, U.; Cocozza, M.; Coto, V.; Policicchio, D.; Carifi, S.; Piermatteo, E.; Lombardi, R.; et al. Evaluation of the clinical efficacy of idebenone in patients affected by chronic cerebrovascular disorders. Arch. Gerontol. Geriatr. 1992, 15, 225-237. [CrossRef]

48. Geromel, V.; Darin, N.; Chretien, D.; Benit, P.; DeLonlay, P.; Rotig, A.; Munnich, A.; Rustin, P. Coenzyme $\mathrm{Q}(10)$ and idebenone in the therapy of respiratory chain diseases: Rationale and comparative benefits. Mol. Genet. Metab. 2002, 77, 21-30. [CrossRef]

49. Pisano, P.; Durand, A.; Autret, E.; Desnuelle, C.; Pinsard, N.; Serratrice, G.; Legout, V.; Joubert, M.; Blin, O. Plasma concentrations and pharmacokinetics of idebenone and its metabolites following single and repeated doses in young patients with mitochondrial encephalomyopathy. Eur. J. Clin. Pharmacol. 1996, 51, 167-169. [CrossRef]

50. Heitz, F.D.; Erb, M.; Anklin, C.; Robay, D.; Pernet, V.; Gueven, N. Idebenone protects against retinal damage and loss of vision in a mouse model of Leber's hereditary optic neuropathy. PLOS ONE 2012, 7, e45182. [CrossRef]

51. Di Prospero, N.A.; Baker, A.; Jeffries, N.; Fischbeck, K.H. Neurological effects of high-dose idebenone in patients with Friedreich's ataxia: A randomised, placebo-controlled trial. Lancet Neurol. 2007, 6, 878-886. [CrossRef]

(C) 2020 by the authors. Licensee MDPI, Basel, Switzerland. This article is an open access article distributed under the terms and conditions of the Creative Commons Attribution (CC BY) license (http://creativecommons.org/licenses/by/4.0/). 